University of Nebraska - Lincoln

DigitalCommons@University of Nebraska - Lincoln

$5-1-2020$

\title{
A New Method to Reconstruct Quantitative Food Webs and Nutrient Flows from Isotope Tracer Addition Experiments
}

Andrés López-Sepulcre

Matthieu Bruneaux

Sarah M. Chinn

Rana W. El-Sabaawi

Alexander S. Flecker

See next page for additional authors

Follow this and additional works at: https://digitalcommons.unl.edu/natrespapers

Part of the Natural Resources and Conservation Commons, Natural Resources Management and Policy Commons, and the Other Environmental Sciences Commons

This Article is brought to you for free and open access by the Natural Resources, School of at DigitalCommons@University of Nebraska - Lincoln. It has been accepted for inclusion in Papers in Natural Resources by an authorized administrator of DigitalCommons@University of Nebraska - Lincoln. 


\section{Authors}

Andrés López-Sepulcre, Matthieu Bruneaux, Sarah M. Chinn, Rana W. El-Sabaawi, Alexander S. Flecker, and Steven A. Thomas 


\title{
A New Method to Reconstruct Quantitative Food Webs and Nutrient Flows from Isotope Tracer Addition Experiments
}

\author{
Andrés López-Sepulcre, ${ }^{1,2, \star}$ Matthieu Bruneaux, ${ }^{2}$ Sarah M. Collins, ${ }^{3}$ Rana El-Sabaawi, ${ }^{4}$ \\ Alexander S. Flecker, ${ }^{5}$ and Steven A. Thomas ${ }^{6}$
}

1. Department of Biology, Washington University in Saint Louis, Saint Louis, Missouri 63130; and CNRS Unité Mixte de Recherche (UMR) 7618, Institute of Ecology and Environmental Sciences of Paris (iEES), Sorbonne Université, Paris, France; 2. Department of Biological and Environmental Sciences, University of Jyväskylä, Jyväskylä, Finland; 3. Department of Zoology and Physiology, University of Wyoming, Laramie, Wyoming 82071; 4. Department of Biology, University of Victoria, Victoria, Canada; 5. Department of Ecology and Evolutionary Biology, Cornell University, Ithaca, New York 14853; 6. School of Natural Resources, University of Nebraska-Lincoln, Lincoln, Nebraska 68583

Submitted March 20, 2019; Accepted December 23, 2019; Electronically published May 1, 2020

Online enhancements: appendix, supplemental PDF. Dryad data: https://doi.org/10.5061/dryad.8sf7m0chx.

\begin{abstract}
AвSTRACт: Understanding how nutrients flow through food webs is central in ecosystem ecology. Tracer addition experiments are powerful tools to reconstruct nutrient flows by adding an isotopically enriched element into an ecosystem and tracking its fate through time. Historically, the design and analysis of tracer studies have varied widely, ranging from descriptive studies to modeling approaches of varying complexity. Increasingly, isotope tracer data are being used to compare ecosystems and analyze experimental manipulations. Currently, a formal statistical framework for analyzing such experiments is lacking, making it impossible to calculate the estimation errors associated with the model fit, the interdependence of compartments, and the uncertainty in the diet of consumers. In this article we develop a method based on Bayesian hidden Markov models and apply it to the analysis of ${ }^{15} \mathrm{~N}-\mathrm{NH}_{4}{ }^{+}$tracer additions in two Trinidadian streams in which light was experimentally manipulated. Through this case study, we illustrate how to estimate $\mathrm{N}$ fluxes between ecosystem compartments, turnover rates of $\mathrm{N}$ within those compartments, and the associated uncertainty. We also show how the method can be used to compare alternative models of food web structure, calculate the error around derived parameters, and make statistical comparisons between sites or treatments.
\end{abstract}

Keywords: food webs, hidden Markov model (HMM), isotope tracer addition, model selection, nutrient uptake, state-space models.

\section{Introduction}

Food webs are the cornerstone of community and ecosystem ecology because they describe the flow of matter and

\footnotetext{
* Corresponding author; email: alopezsepulcre@wustl.edu. ORCIDs: López-Sepulcre, https://orcid.org/0000-0001-9708-0788; Bruneaux, https://orcid.org/0000-0001-6997-192X; Collins, https://orcid.org/0000-0001-5503 -7386; El-Sabaawi, https://orcid.org/0000-0002-0561-1068; Flecker, https://orcid .org/0000-0002-4636-2109; Thomas, https://orcid.org/0000-0002-5249-3500.
}

Am. Nat. 2020. Vol. 195, pp. 964-982. (C) 2020 by The University of Chicago. 0003-0147/2020/19506-59131\$15.00. All rights reserved.

DOI: $10.1086 / 708546$ energy among organisms, thus defining important properties of an ecosystem, such as stability and productivity (Paine 1980; Newbold et al. 1983; Carpenter et al. 2005; Rooney and McCann 2012). They provide the raw material for many ecological questions, including the study of trophic cascades, nutrient cycling, and ecosystem productivity. Food web studies have been a major theme in ecological research for more than a century, beginning with early work that identified trophic linkages (Elton 1927). More recent studies have attempted to quantitatively track the movement of energy and materials through food web compartments, which remains particularly challenging because of complex methods for both data collection and analysis (Dodds et al. 2014).

While interaction strength has been defined in a variety of ways throughout the literature, ecosystem scientists are often interested in the biomass flux of a given nutrient between two species or compartments (Berlow et al. 2004). Researchers have used a variety of approaches to estimate trophic fluxes in the past, including gut-content analysis (Ledger et al. 2013) and analysis of egested material (such as feces or pellets; Lima et al. 2002; Roslin and Majaneva 2016). These methods, however, are sensitive to sampling effects (Banašek-Richter et al. 2004) and only consider what is ingested, rarely accounting for what is assimilated into tissue, and therefore they may not provide accurate estimates of how matter and energy flows through an ecosystem. Another approach is stable isotope analysis, which uses natural variation in the abundance of stable isotopes (most often ${ }^{13} \mathrm{C},{ }^{15} \mathrm{~N}$, or ${ }^{2} \mathrm{H}$ ) across organisms to infer trophic relations (Peterson and Fry 1987; Boecklen et al. 2011). While these natural abundance isotope webs offer a more integrative picture of diet and directly target assimilated nutrients, they are often descriptive and unable to quantify 
fluxes. Moreover, results are sensitive to the assumptions of diet-mixing models (Post 2002; Bond and Diamond 2011) and often fail to differentiate carbon sources in freshwater ecosystems (Jardine et al. 2014). A powerful alternative is using whole-ecosystem isotope addition experiments to estimate fluxes across trophic compartments and characterize nutrient cycles (Newbold et al. 1983; Kling 1994; Carpenter et al. 2005).

Isotope tracer additions use small amounts of isotopically enriched nutrients to track the movement of nutrient tracers among different ecosystem compartments through time. Depending on the properties of the ecosystem, isotopes are added all at once (pulse design) or at a constant rate over a period of time (press design). The pulse design was used in early additions of radioisotopes to lakes (Hutchinson and Bowen 1950; Rigler 1956), streams (Ball and Hooper 1963; Elwood and Nelson, 1972; Newbold et al. 1983), and meso- and microcosms (Whittaker 1961; Patten and Witkamp 1967). Whittaker (1961) pioneered the use of a linear donor-controlled compartment model to quantify transfers of the tracer through the food web, an approach also applied by Patten and Witkamp (1967) and by Newbold et al. (1983). For their whole-stream addition of ${ }^{32} \mathrm{P}$, Newbold et al. (1983) calculated transfer fluxes of the naturally occurring phosphorus from the steady-state solution of the compartment model. In press additions, the tracer accumulates in specific ecosystem compartments until an equilibrium state is achieved or the addition ends. Once the addition stops, the tracer begins to clear from basal compartments (e.g., algae) and, progressively after, from higher trophic levels. This design has been used extensively in stream ecosystems to estimate nutrient uptake and turnover (Dodds et al. 2000; Mulholland et al. 2000).

Complemented with estimates of compartment sizes (biomasses), isotopic additions allow for the estimation of nutrient uptake and turnover rates for all ecosystem compartments as well as quantification of the fluxes between them (Dodds et al. 2000; Mulholland et al. 2000). This tracer addition approach has been used to characterize a variety of systems, including nitrogen $\left({ }^{15} \mathrm{~N}\right)$ in streams (summarized by Dodds et al. 2014) and forests (Goodale et al. 2015), carbon $\left({ }^{13} \mathrm{C}\right)$ in marine and lake ecosystems (Middelburg et al. 2000; Cole et al. 2002; Pace et al. 2004), and deuterium-labeled water $\left({ }^{2} \mathrm{H}_{2} \mathrm{O}\right)$ in terrestrial ecosystems (Kulmatiski et al. 2010).

Despite the increase in their use, there is no formal statistical framework to analyze whole-ecosystem data from tracer addition experiments. Instead, each trophic linkage is analyzed separately, solving for a mass balance between tracer uptake and turnover under the following assumptions: (1) the source pools from which a consumer obtains nutrients are known; (2) if there is more than one source, the proportional contribution of each source is known;
(3) the added isotope is instantaneously and perfectly mixed within a compartment; and (4) consumers do not prey selectively within a source compartment (i.e., the isotopic signature of the matter taken up reflects the signature of the source; Dodds et al. 2000; Mulholland et al. 2000). Some of these assumptions can be problematic. First, trophic links can be uncertain, and even when every consumer's source compartment is known, estimates of their proportional contribution tend to be crude approximations (Ainsworth et al. 2010). Second, consumers often differentially assimilate components of their diet or selectively feed on specific portions of a sampled compartment. If not accounted for, this can cause seemingly paradoxical results, where consumers are more enriched with the tracer than the resource they feed on (Dodds et al. 2014). Regardless of their assumptions, neither of these approaches allows error in the inferences of parameters at lower trophic levels to propagate into flux estimates at higher trophic levels. Nor can they estimate and incorporate the error associated with uncertainty in trophic relationships or diet proportions. With the increase in the use of isotope tracer additions in comparative studies (Dodds et al. 2014; Norman et al. 2017; Tank et al. 2018) and ecosystem-scale experiments (Whiles et al. 2013; Collins et al. 2016), it has become imperative to develop a statistical framework that allows rigorous comparisons among systems and treatments.

To meet this need, we developed a novel approach to the statistical analysis of isotope tracer data based on Bayesian hidden Markov models (HMMs; Zucchini and MacDonald 2009; King 2014). Our approach allows for simultaneous modeling of nutrient transfers among all measured ecosystem compartments, providing estimations of parameter uncertainty that account for both observation and process error propagating across compartments. For omnivores, our method does not require a priori assumptions on the proportion of different prey constituting the diet but rather estimates the proportion as a model parameter. It also allows the modeling of nonhomogeneous compartments by estimating actively cycling versus refractionary proportions, thus accounting for overenriched signatures in consumers. Moreover, when there are doubts in the topology of the food web (e.g., whether a particular predator eats a specific prey or not), model comparison tools can be used to choose between the most parsimonious structure according to the data.

We first present the mathematical and statistical framework, framed as a HMM (Zucchini and MacDonald 2009), and then demonstrate its application with a case study on two Trinidadian montane streams differing in canopy cover (Collins et al. 2016). We illustrate how the approach can be used to (1) estimate model parameters and their uncertainty; (2) calculate derived properties, such as nutrient fluxes and compartment residence times, and their 
uncertainty; (3) test alternative food web topologies; and (4) statistically compare experimental treatments.

\section{Modeling Tracer Dynamics}

\section{Mathematical Framework}

The transfer of nutrients from one compartment to the other can be represented as a Markov chain, a probabilistic model where the state of a given system (i.e., the distribution of nutrients across compartments) at time $t$ depends only on its previous state at time $t-1$ (Iosifescu 1980). In a HMM, dynamic data are modeled as a consequence of two stochastic processes: an unobserved biological pro- cess (here, nutrient fluxes) and an observation process that is conditional on the biological process (in our case, sampling and measurement of isotopic ratios). Table 1 shows a summary of the parameter notation followed and units of measurement used.

We conceptualize an ecosystem as a population of nutrient atoms flowing between compartments of an ecosystem. These compartments correspond, in HMM terminology, to the possible states a nutrient atom can be in. For a given ecosystem with a set of $C$ compartments, we can define the distribution of atoms among compartments at time $t$ as a $C \times 1$ vector $\mathbf{x}^{(t)}=\left\{x_{1}^{(t)}, x_{2}^{(t)}, \ldots, x_{N}^{(t)}\right\}$, where $x_{i}^{(t)}$ indicates the number of nutrient atoms in compartment $i$ at time $t$. We can then define a $C \times C$ transition matrix $\boldsymbol{\Psi}$ where each

Table 1: Notation

\begin{tabular}{|c|c|c|c|}
\hline Parameter & Description & Domain & Unit \\
\hline \multicolumn{4}{|c|}{ Observed variables: } \\
\hline C & Number of ecosystem compartments & $\mathbb{N}$ & $\ldots$ \\
\hline $\mathcal{I}$ & Set of dissolved inorganic nutrient compartments & $\ldots$ & $\ldots$ \\
\hline $\mathcal{B}$ & Set of basal resources uptaking dissolved nutrients & $\ldots$ & $\ldots$ \\
\hline$x_{\mathrm{obs}, i}^{(s, t)}$ & Biomass of compartment $i$ at sampling point $s$ and time $t$ & $(0, \infty)$ & $\mathrm{mgN} \mathrm{m}^{-2}$ \\
\hline$z_{\mathrm{obs}, i}^{(s, t)}$ & $\begin{array}{l}\text { Proportion of marked isotope in compartment } i \text { at sampling } \\
\text { point } s \text { and time } t\end{array}$ & $(0,1)$ & 1 \\
\hline $\mathrm{SD}_{i}$ & Standard deviation of compartment biomasses $x_{i}$ & $(0,1)$ & 1 \\
\hline \multicolumn{4}{|c|}{ State variables: } \\
\hline $\mathbf{x}^{(s, t)}$ & $\begin{array}{l}C \times 1 \text { vector of elements } x_{i}^{(s, t)}=\text { nutrient mass in compartment } i \\
\text { at sampling point } s \text { and time } t\end{array}$ & $(0, \infty)$ & $\mathrm{mgN} \mathrm{m}{ }^{-2}$ \\
\hline $\mathbf{n}^{(s, t)}$ & $\begin{array}{l}C \times 1 \text { vector of elements } n_{i}^{(s, t)}=\text { unmarked nutrient mass in } \\
\text { compartment } i \text { at sampling point } s \text { and time } t\end{array}$ & $(0, \infty)$ & $\mathrm{mgN} \mathrm{m}^{-2}$ \\
\hline $\mathbf{m}^{(s, t)}$ & $\begin{array}{l}C \times 1 \text { vector of elements } m_{i}^{(s, t)}=\text { marked nutrient mass in } \\
\text { compartment } i \text { at sampling point } s \text { and time } t\end{array}$ & $(0, \infty)$ & $\mathrm{mgN} \mathrm{m}{ }^{-2}$ \\
\hline $\mathbf{z}^{(s, t)}$ & $\begin{array}{l}C \times 1 \text { vector of elements } z_{i}^{(s, t)}=\text { proportion of heavy isotope for } \\
\text { compartment } i \text { at sampling point } s \text { and time } t\end{array}$ & $(0,1)$ & 1 \\
\hline $\mathbf{y}_{\mathbf{n}}^{(s, t)}$ & $\begin{array}{l}C \times 1 \text { vector of elements } y_{n, i}^{(s)}=\text { external input of unmarked } \\
\text { nutrient into } i \text { at sampling point } s \text { and time } t\end{array}$ & $(0, \infty)$ & $\mathrm{mgN} \mathrm{m}^{-2}$ \\
\hline $\mathbf{y}_{\mathrm{m}}^{(s, t)}$ & $\begin{array}{l}C \times 1 \text { vector of elements } y_{m, i}^{(s)}=\text { external input of marked } \\
\text { nutrient into } i \text { at sampling point } s \text { and time } t\end{array}$ & $(0, \infty)$ & $\mathrm{mgN} \mathrm{m}{ }^{-2}$ \\
\hline \multicolumn{4}{|c|}{ Estimated parameters: } \\
\hline$\Psi_{\mathrm{h}}$ & $\begin{array}{l}\text { Transition matrix of elements } \psi_{i, j}=\text { rate of nutrient transition } \\
\text { between compartments } j \text { and } i \text { under model } \mathbf{h}\end{array}$ & $(0,1)$ & day $^{-1}$ \\
\hline$v_{i, j}$ & Uptake rate from compartment $j$ to $i$ & $(0,1)$ & day $^{-1}$ \\
\hline$\lambda_{i}$ & Loss rate of compartment $i$ & $(0,1)$ & day $^{-1}$ \\
\hline$k_{i}$ & Turnover rate of compartment $i$ & $(0,1)$ & day $^{-1}$ \\
\hline$\pi_{i}$ & Active (i.e., nonrefractory) portion of compartment $i$ & $(0,1)$ & 1 \\
\hline$\eta$ & Coefficient of variation of the isotopic proportions $z_{i, j}$ & $(0,1)$ & 1 \\
\hline \multicolumn{4}{|c|}{ Derived parameters: } \\
\hline$\hat{X}_{i}$ & Expected steady-state biomass of compartment $i$ & $(0, \infty)$ & $\mathrm{mgN} \mathrm{m} \mathrm{m}^{-2}$ \\
\hline$T_{i}$ & Turnover time of the active portion of compartment $i$ & $(0, \infty)$ & day \\
\hline$T_{i}^{\prime}$ & Apparent turnover time of compartment $i$ & $(0, \infty)$ & day \\
\hline$F_{i, j}$ & Flux between compartment $j$ and $i$ & $(0, \infty)$ & $m g N m^{-2}$ day $^{-1}$ \\
\hline$F_{T}$ & Total nutrient flux & $(0, \infty)$ & $\mathrm{mgN} \mathrm{m}^{-2}$ day $^{-1}$ \\
\hline$P_{i, j}^{U}$ & Proportion of compartment $i$ s total uptake coming from $j$ & $(0,1)$ & 1 \\
\hline$P_{i, j}^{K}$ & Proportion of compartment $j$ s turnover due to uptake by $i$ & $(0,1)$ & 1 \\
\hline
\end{tabular}


element $\psi_{i, j}$ defines the probability that an atom of nutrient in compartment $j$ at time $t$ finds itself in compartment $i$ at time $t+1$. Some of the compartments, such the inorganic nutrient forms, may receive external inputs between $t$ and $t+1$, which can be defined as nonzero elements in a $C \times 1$ vector of external inputs $\mathbf{y}^{(t)}=\left\{y_{1}^{(t)}, y_{2}^{(t)}, \ldots, y_{N}^{(t)}\right\}$ defined by input functions $f_{i}: t \rightarrow y_{i}^{(t)}$. Given this, we can project the distribution of nutrients from time $t$ to $t+1$ using the equation

$$
\mathbf{x}^{(t+1)}=\Psi \cdot \mathbf{x}^{(t)}+\mathbf{y}^{(t)} .
$$

This is a discretized form of the linear donor-controlled compartment model proposed by Mulholland and Keener (1974). The transition probabilities $\psi_{i, j}$ in $\boldsymbol{\Psi}$ are determined by two processes: nutrient uptake and nutrient loss. Uptake rates determine the probability that a nutrient atom moves from compartment $j$ to $i$ in one time step and are defined as $v_{i, j}>0$ for every pair of compartments, where compartment $i$ uses compartment $j$ as a source of nutrient. Loss rates $\lambda_{j}$ represent the probability that a nutrient atom leaves compartment $j$ within one time step without being taken up by any other compartment, thus exiting the modeled ecosystem. The turnover rate $k_{j}$ of a given compartment $j$ (i.e., the proportion of nutrient exiting a given compartment per unit time) will be determined by the sum of the proportion consumed by other compartments and the proportion lost $\lambda_{j}$.

$$
k_{j}=\lambda_{j}+\sum_{i=1}^{C} v_{i, j} .
$$

In other words, equation (1) is equivalent to stating that the nutrient dynamics of any given compartment $j$ is described by the time-specific change in nutrient content:

$$
\Delta x_{j}^{(t)}=\sum_{1 \leq i \leq C, i \neq j} v_{j, i} x_{j}^{(t)}-k_{j} x_{j}^{(t)}+y_{j}^{(t)},
$$

which can be simplified in the case where $y_{j}^{(t)}=0$ (i.e., no external input for compartment $j$ ) to

$$
\Delta x_{j}^{(t)}=\sum_{1 \leq i \leq C, i \neq j} v_{j, i} x_{j}^{(t)}-k_{j} x_{j}^{(t)}
$$

For example, let us consider a simple ecosystem with four compartments: an inorganic nutrient pool, a primary producer, a herbivore that consumes the primary producer, and an omnivore that feeds on both the primary consumer and the herbivore (fig. 1). Such system would be defined by the following $4 \times 4$ transition matrix:

$$
\Psi=\left[\begin{array}{cccc}
1-k_{1} & 0 & 0 & 0 \\
v_{2,1} & 1-k_{2} & 0 & 0 \\
0 & v_{3,2} & 1-k_{3} & 0 \\
0 & v_{4,2} & v_{4,3} & 1-k_{4}
\end{array}\right]
$$

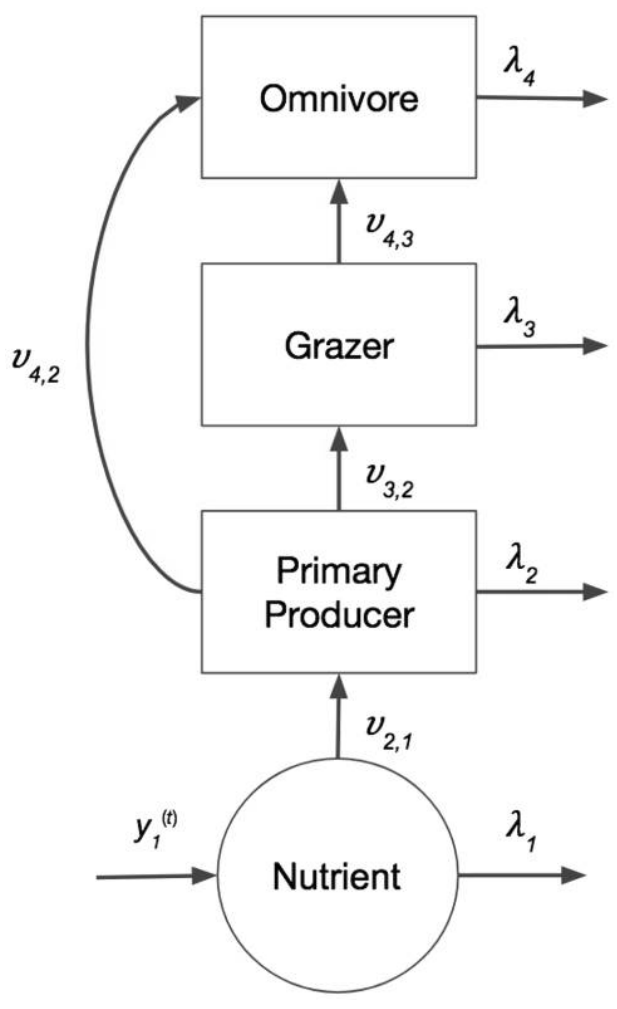

Figure 1: Schematic example/representation of a hidden Markov model and food web matrix.

and an exogenous input vector $\mathbf{y}^{(t)}=\left\{y_{1}^{(t)}, 0,0,0\right\}$. Note that if we assume the concentration of inorganic nutrient to be at a steady-state equilibrium $\left(x_{1}^{(t)}=x_{1}^{\left(t_{0}\right)}\right.$ does not depend on time), it must fulfill that

$$
\begin{aligned}
\forall t, \quad \frac{\Delta x_{1}^{(t)}}{\Delta t}=0 & \Leftrightarrow y_{1}^{(t)}-k_{1} x_{1}^{(t)}=0 \\
& \Leftrightarrow y_{1}^{(t)}=\left(v_{2,1}+\lambda_{1}\right) x_{1}^{\left(t_{0}\right)} ;
\end{aligned}
$$

thus, $y_{1}$ does not depend on $t$. Note also that it is straightforward to modify these equations describing a discretetime system to describe a continuous-time system. In this case, equation (1) becomes

$$
\frac{d \mathbf{x}^{(t)}}{d t}=\Psi \cdot \mathbf{x}^{(t)}+\mathbf{y}^{(t)}
$$

with $\Psi \cdot \mathbf{x}^{(t)}$ and $\mathbf{y}^{(t)}$ describing instantaneous transition rates and input rates, respectively, instead of transition probabilities and input per time step. Equation (8) is basically a system of inhomogeneous linear differential equations (which simplifies into a homogeneous system if $\left.\mathbf{y}^{(t)}=0\right)$. The transition matrix $\boldsymbol{\Psi}$ for a continuous-time 
model corresponding to the ecosystem shown in figure 1 becomes (compare with eq. [5])

$$
\boldsymbol{\Psi}=\left[\begin{array}{cccc}
-k_{1} & 0 & 0 & 0 \\
v_{2,1} & -k_{2} & 0 & 0 \\
0 & v_{3,2} & -k_{3} & 0 \\
0 & v_{4,2} & v_{4,3} & -k_{4}
\end{array}\right]
$$

The choice between a discrete and a continuous model depends on the biology of the system under study. We use a continuous model in the case study of Trinidadian montane streams presented below.

In the case of tracer addition experiments, the aim is to increase the exogenous input of a tracer (or marked) nutrient population and track the changes in the ratio between marked and unmarked nutrient (atomic ratio, in the case of isotope tracers). The addition of marked nutrient should cause a significant enrichment of the proportion of marked nutrient in water yet a marginal increase in the total amount of nutrient in water. This can be achieved, for example, by using rare isotopic forms (e.g., ${ }^{15} \mathrm{~N},{ }^{13} \mathrm{C},{ }^{18} \mathrm{O}$, or $\left.{ }^{2} \mathrm{H}\right)$ that occur at extremely low proportions in nature. To model this, it is therefore necessary to follow two subpopulations of nutrient atoms: a tracer (or marked) population, usually the heavy isotopic form, and an unmarked population, defined by vectors $\mathbf{m}^{(t)}=\left\{m_{1}^{(t)}, \ldots, m_{C}^{(t)}\right\}$ and $\mathbf{n}^{(t)}=\left\{n_{1}^{(t)}, \ldots, n_{C}^{(t)}\right\}$, respectively, which add up to the total nutrient population $\mathbf{x}^{(t)}=\mathbf{n}^{(t)}+\mathbf{m}^{(t)}$. The proportion of tracer can then be defined as

$$
\mathbf{z}^{(t)}=\mathbf{m}^{(t)} \oslash \mathbf{x}^{(t)},
$$

where $\oslash$ stands for the element-by-element division, also known as Hadamard division. Similarly, the exogenous input comprises marked $\mathbf{y}_{\mathbf{m}}^{(t)}$ and unmarked $\mathbf{y}_{\mathbf{n}}^{(t)}$ portions, such that $\mathbf{y}^{(\mathbf{t})}=\mathbf{y}_{\mathbf{n}}{ }^{(t)}+\mathbf{y}_{\mathbf{m}}{ }^{(t)}$. In a tracer addition experiment, the marked nutrient should be at much lower concentration than the unmarked nutrient, such that $\mathbf{y}_{\mathbf{m}}{ }^{(t)} \ll$ $\mathbf{y}_{\mathbf{n}}{ }^{(t)}$, and therefore $\mathbf{y}^{(t)} \approx \mathbf{y}_{\mathbf{n}}{ }^{(t)}$.

The schedule of tracer addition is reflected in the exogenous input vector of marked material $\mathbf{y}_{\mathbf{m}}^{(t)}$ and usually consists of a period of increased input for one or two inorganic nutrient pools (e.g., $\mathrm{NH}_{4}{ }^{+}$or $\mathrm{NO}_{3}{ }^{-}$) followed by a period of background input (although other experimental designs, such as repeated pulses, can be easily defined). The exogenous input for the unmarked population $\mathbf{y}_{\mathbf{n}}^{(t)}$ is normally assumed constant.

Once we have an expected realization of the biological process model, the observation process can be modeled as sampling and measurement error around that expectation. The observed proportion of marked tracer in any given compartment $i$ at time $t$ can be modeled as a gamma distribution, which fulfills the multiplicative properties of proportions and allows for the skewed distribution typical of low-concentration data. We parameterized the gamma distribution with the projected mean $z_{i}^{(t)}$ and a coefficient of variation $\eta$ shared across compartments, such that the observed proportion $z_{\mathrm{obs}, i}^{(t)}$ follows (using Gamma* to denote the nonstandard gamma parameterization):

$$
z_{\mathrm{obs}, i}^{(t)} \sim \operatorname{Gamma}^{*}\left(z_{i}^{(t)}, \eta\right) .
$$

This is equivalent to modeling gamma distributions with shape parameter $\alpha_{i}=\eta^{-2}$ and rate parameter $\beta_{i}=$ $\left(z_{i}^{(t)} \cdot \eta^{2}\right)^{-1}$. Although the gamma distribution can hypothetically reach values larger than 1 , the expected isotopic proportions are extremely low, and therefore the probability density for values higher than 1 is negligible.

We will assume the total biomass of nitrogen $x_{i}$ in compartment $i$ to be approximately constant throughout the experiment, following a truncated normal distribution. This assumes additive properties and allows for zero values of biomass, which can occur for a given compartment in some sampling points. We note the truncated normal distribution with a mean $x_{i}^{(t 0)}$ (the initial biomass of compartment i) and a compartment-specific standard deviation $\mathrm{SD}_{i}$ :

$$
x_{i}^{(t)} \sim \mathrm{TNorm}_{\text {lower }=0}\left(x_{i}^{(t 0)}, \mathrm{SD}_{i}\right)
$$

\section{Overenriched Compartments}

The model as formulated above assumes that the tracer is well mixed and that consumers do not selectively feed on differently labeled subcomponents of the source compartment. If this is true, the tracer signature of a consumer cannot exceed the signature of the source compartment. In practice, however, it is not uncommon for a consumer's isotopic label to be higher than its resource (Newbold et al. 1983; Dodds et al. 2014). This is because some compartments, particularly detrital ones, consist of material in which only a proportion is biologically active and assimilating tracer during the experiment. If consumers selectively feed on active constituents and/or preferentially assimilate active fractions, their signature can become higher than the average of the resource compartment. For example, coarse benthic organic matter (CBOM) is largely biologically inactive, and nutrient uptake into leaf packs is associated with the biofilm surrounding it. While the average tracer signal measured on the whole compartment might be low, the biofilm can have a high tracer signature, and organisms selectively feeding on (or assimilating) that biofilm will become highly labeled.

To allow for this in the model, one can assume that the biomass of any given compartment $i$ is split into two portions: an active one and a refractory one. The active portion takes up nutrients throughout the experiment and contributes to changes in $x_{i}^{(t)}$ (both $m_{i}^{(t)}$ and $n_{i}^{(t)}$ ). The refractory portion has negligible nutrient uptake and turnover within 
the time span of the experiment and thus does not contribute to changes in $x_{i}^{(t)}$. If we define a vector of active proportions for the $C$ compartments $\pi=\left\{\pi_{1}, \ldots, \pi_{C}\right\}$ where $0<\pi_{i}<1$ whenever compartment $i$ is assumed to be nonhomogeneous, the apparent uptake rates $v_{i, \text {, and }}^{\prime}$ apparent turnover rate $k_{i}^{\prime}$ of the whole compartment will be:

$$
\begin{aligned}
v_{i, .}^{\prime} & =v_{i, .} \cdot \pi_{i}, \\
k_{i}^{\prime} & =k_{i} \cdot \pi_{i} .
\end{aligned}
$$

In practice, this means that while the biological model (eq. [5]) runs only on the active portion of biomass, the observation model accounts for the total biomass. Newbold et al. (1983) preceded the present article in recognizing that the standing stocks of the actively cycling components (as well as transfer fluxes) can be estimated from the model's steady-state solution. Note that $\pi$ bears a similar meaning to the estimates of exchangeable P in Newbold et al. (1983) and the inverse of multiplier $M$ in Dodds et al. (2014).

\section{Model Fitting}

Fitting the above HMM requires time series of the observed tracer proportions $z_{\mathrm{obs}, i}^{(t)}$ in each compartment and data on compartment biomasses $x_{\mathrm{obs}, i}^{(t)}$. In isotope tracer studies where there is a heavy isotope (the marked tracer) and a light (unmarked) isotope, the amount of marked tracer will often be expressed as a $\delta$ value. For example, in studies of nitrogen dynamics, the tracer is ${ }^{15} \mathrm{~N}$ (heavier than the naturally common ${ }^{14} \mathrm{~N}$ ), and data are obtained as $\delta^{15} \mathrm{~N}$, which for any given compartment $i$ at time $t$ is

$$
\delta^{15} \mathrm{~N}_{i}^{(t)}=\left(\frac{R_{i}^{(t)}}{R_{0}}-1\right) \cdot 1,000,
$$

where $R_{i}^{(t)}=\left({ }^{15} \mathrm{~N} /{ }^{14} \mathrm{~N}\right)_{i}^{(t)}$ is the isotopic ratio in compartment $i$ at time $t$ and $R_{0}$ is the isotopic ratio in a standard air sample (e.g., for ${ }^{15} \mathrm{~N}$ this is taken to be 0.003663 ). To fit the above-described model to these data, it is necessary to convert the $\delta$ values to observed proportions. This can be done by expressing $z_{\mathrm{obs}, i}^{(t)}$ as a function of $R_{i}^{(t)}$,

$$
z_{\mathrm{obs}, i}^{(t)}=\frac{m_{i}^{(t)}}{n_{i}^{(t)}+m_{i}^{(t)}}=\frac{{ }^{15} \mathrm{~N}_{i}^{(t)}}{{ }^{14} \mathrm{~N}_{i}^{(t)}+{ }^{15} \mathrm{~N}_{i}^{(t)}}=\frac{R_{i}^{(t)}}{R_{i}^{(t)}+1},
$$

and then using a rearrangement of equation (15) to replace $R_{i}^{(t)}$ in the equation for $z_{\mathrm{obs}, i}^{(t)}$ :

$$
z_{\mathrm{obs}, i}^{(t)}=R_{0}\left(\frac{\delta^{15} \mathrm{~N}_{i}^{(t)}}{1,000}+1\right)\left[R_{0}\left(\frac{\delta^{15} \mathrm{~N}_{i}^{(t)}}{1,000}+1\right)+1\right]^{-1} .
$$

Given these data and an assumed system topology denoting which compartment pairs are assumed to be linked as consumer and resource (i.e., which off-diagonal elements $\psi_{i, j}>0$ ), we can fit the model to the data using a Bayes- ian framework. To do so, we need to define priors for all $v_{i, j} \geq 0,0 \leq \pi_{i} \leq 1, \lambda_{i}$, and $\eta$. These can be uninformative (i.e., flat) distributions within the parameter bounds or informative priors if there is prior knowledge on these quantities. For parameters that are positive but for which no upper bound is known precisely a priori, a half-Cauchy distribution defined by its scale parameter (i.e., its median) is a reasonable choice. In the case study of Trinidadian montane streams presented below, we used half-Cauchy priors for the uptake rates from the inorganic input compartments, since those compartments are constantly being renewed with the stream flow. For uptake rates and loss rates from biotic compartments, we used (scaled) beta priors to impose a maximum rate while allowing more prior belief to be put in small rate values: for example, it is unreasonable to allow uptake or loss rates greater than 1 with our data, since this would indicate a replacement of the whole nitrogen content of a biotic compartment within 1 day. Hence, we started our modeling approach with the following weakly informative priors:

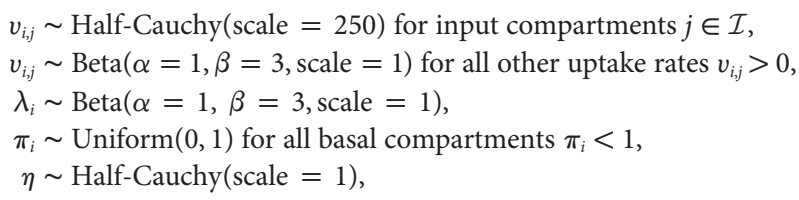

where $\mathcal{I}$ defines the set of inorganic nutrient compartments. We adjusted them for some parameters after realizing from initial runs that they could be either too restrictive or too permissive, depending on the compartments:

$$
\begin{aligned}
v_{\text {eudan, } \mathrm{CBOM}} & \sim \operatorname{Beta}(\alpha=1, \beta=3, \text { scale }=0.5), \\
v_{\text {lepto,seston }} & \sim \operatorname{Beta}(\alpha=1, \beta=3, \text { scale }=0.5) .
\end{aligned}
$$

In the formulation above, we define $X$ as following a scaled beta distribution $\operatorname{Beta}(\alpha, \beta$, scale) if $X /$ scale follows a beta distribution $\operatorname{Beta}(\alpha, \beta)$.

The likelihood $\mathcal{L}$ of each observation $z_{\text {obs }, i}^{(t)}$ is given by equation (11), and the joint log likelihood of all observations is given as the sum of logarithms of all individual likelihoods. To help identifiability, the model can be constrained so that the total nutrient biomass of each compartment $x_{i}$ is randomly distributed with known constant mean and standard deviation $\mathrm{SD}_{i}$, as described in equation (12). These values can be obtained from independent estimations of compartment-specific biomasses $x_{\mathrm{obs}, i \cdot}$. The likelihood of each biomass $x_{i}^{(t)}$ projected by the model is evaluated against this distribution at each time point where there is any observation $z_{\mathrm{obs}, i}^{(t)}$ in order to constrain the biomass change of the system compartments in the model. The posterior distribution of the parameters can be obtained by sampling the product of prior and likelihood using Markov chain Monte Carlo (MCMC) techniques (Geman and Geman 1984). 


\section{Model Selection, Derived Properties, and Statistical Comparisons}

If there is uncertainty over the presence or absence of any given trophic link, it is possible to define and fit alternative models representing different hypothesized food web topologies $\Psi_{h}$ differing in whether particular uptake rates $v_{i, j}$ are equal to zero. The model fits can then be compared using the deviance information criterion (DIC; Spiegelhalter et al. 2002), defined as

$$
\mathrm{DIC}=\bar{D}+p_{D},
$$

where $D$ is the set of deviance values calculated from the $\log$-likelihood value at each MCMC iteration as $-2 \cdot \log \mathcal{L}$, $\bar{D}$ is the mean deviance value, and $p_{D}$ is the effective number of parameters in the model and can be calculated as $\operatorname{var}(D) / 2$ (Gelman et al. 2003). The most parsimonious model will be the one with the lowest DIC. A DIC difference $(\Delta \mathrm{DIC})$ greater than 2 indicates some evidence for the model with a lower DIC, while substantial evidence would be indicated by $\Delta \mathrm{DIC}>5$. It is also possible to compare the proportional support for any given model $\Psi_{h}$ as a DIC weight (Link and Barker 2010):

$$
w_{h}=\frac{\exp \left(\Delta \mathrm{DIC}_{h} / 2\right)}{\sum_{g=1}^{M} \exp \left(\Delta \mathrm{DIC}_{g} / 2\right)},
$$

where $h$ represents the model hypothesis in question, $\Delta \mathrm{DIC}_{i}$ is the DIC difference between the most parsimonious model and model $i$, and $M$ represents the total number of models tested.

Any derived metric of the system, such as total uptake and residence times of different compartments or proportion of a given prey in a consumer's diet, can be calculated using the MCMC chains of the parameter estimates involved in the calculations. This will produce an equally sized MCMC chain from which to create the distribution of the metric and its uncertainty (e.g., 95\% credible intervals). Similarly, one can compare estimates of parameters or derived metrics between streams by subtracting (or dividing) the MCMC chains of the two estimates and producing a distribution and credible intervals of the difference in the estimates. The $95 \%$ credible intervals of statistically significant differences should not overlap zero (or 1 for ratios).

\section{Case Study: Nitrogen Fluxes in Trinidadian Montane Streams}

\section{Study System and Experimental Methods}

As an empirical illustration of our statistical modeling framework, we showcase its use in a case study conducted in Trinidadian streams, using simultaneous ${ }^{15} \mathrm{~N}$ tracer isotope additions to evaluate the effects of an experimental manipulation of light availability on major food web fluxes.
These experiments were carried out in streams of the Northern Range of Trinidad: Upper La Laja (UL) and Lower La Laja (LL). The study reaches are 100 and $156 \mathrm{~m}$ long, respectively, and form part of a long-term experiment to study interactions between ecological and evolutionary processes (Travis et al. 2014). These data have been previously analyzed using current methodology in Collins et al. (2016), providing a good point of comparison between the current method and our proposed modeling.

Details on the experiment and sampling can be found in Collins et al. (2016). In summary, we established a continuous drip of a solution of ${ }^{15} \mathrm{~N}$-labeled ammonium (as dissolved ${ }^{15} \mathrm{NH}_{4} \mathrm{Cl}$ ) on the upstream end of each stream with a rate of $10 \mathrm{~mL} \mathrm{m^{-1 }}$ over a 10-day period from March 7 to 16,2010 . The $\mathrm{N}$ injections increased the $\delta^{15} \mathrm{~N}$ of dissolved ammonium to approximately 20,000, yet the concentration of ammonium added was below $5 \%$ of ambient $\mathrm{NH}_{4}$ and thus did not enrich the stream. We sampled the biomass of food web compartments and water chemistry at approximately 15,30 , and $60 \mathrm{~m}$ downstream, in both pool and riffle habitat, on days 3, 7, and 10 of the injection and on days $13,17,20,30$, and 40 postinjection. The sampled food web compartments include water chemistry $\left(\mathrm{NH}_{4}{ }^{+}\right.$and $\left.\mathrm{NO}_{3}{ }^{-}\right)$, basal resources (epilithon, seston, fine benthic organic matter [FBOM], and CBOM), eight common invertebrate taxa representing all major functional feeding groups including grazers (Petrophila and Psephenus), filterers (Leptonema), collectors (Tricorythodes, Phylloicus, and Eudaniela), and predators (Argia and Euthyplocia). For simplicity, fish were not included in this illustrative analysis. For each of the 14 compartments we analyzed the isotopic ratio $\left(\delta^{15} \mathrm{~N}\right)$ of the samples obtained through time and estimated the standing biomass of each compartment in mass of nitrogen per square meter at three points in time. We also collected background samples from each compartment, either before the experiment or upstream from the injection, to estimate background isotopic values. We detail the analytical methods in the appendix (available online).

\section{Model Specification and Selection}

The Trinidadian stream web modeled is composed of the 14 compartments described above. Therefore, the distribution of nitrogen biomasses at any given time $t$ is described by the vector

$\mathbf{x}^{(t)}=\left\{x_{\mathrm{NH} 4}^{(t)}, x_{\mathrm{NO} 3}^{(t)}, x_{\mathrm{epi}}^{(t)}, x_{\mathrm{ses}}^{(t)}, x_{\mathrm{FBOM}}^{(t)}, x_{\mathrm{CBOM}}^{(t)}, x_{\mathrm{pet}}^{(t)}, x_{\mathrm{pse}}^{(t)}, x_{\text {lep }}^{(t)}, x_{\mathrm{tri}}^{(t)}, x_{\text {eud }}^{(t)}, x_{\mathrm{phy}}^{(t)}, x_{\mathrm{arg}}^{(t)}, x_{\mathrm{eut}}^{(t)}\right\}$,

which can be projected following the system of differential equations shown in equation (8), given a transition matrix $\Psi$ of trophic relationships. Given the uncertainty of some trophic links, we test eight variations of the food web structure assumed by Collins et al. (2016), which corresponds to the matrix shown in box 1 . 


\begin{tabular}{|c|c|c|c|c|c|c|c|c|c|c|c|c|c|c|}
\hline \multirow{15}{*}{$\Psi_{111}=$} & \multicolumn{14}{|c|}{ Box 1: Transition matrix describing the food web structure assumed by Collins et al. (2016) } \\
\hline & $\psi_{1,1}$ & 0 & 0 & 0 & 0 & 0 & 0 & 0 & 0 & 0 & 0 & 0 & 0 & 0 \\
\hline & 0 & $\psi_{2,2}$ & 0 & 0 & 0 & 0 & 0 & 0 & 0 & 0 & 0 & 0 & 0 & 0 \\
\hline & $v_{\text {epi,NH4 }}$ & $v_{\text {epi,NO3 }}$ & $-\lambda_{\text {epi }}$ & 0 & 0 & 0 & 0 & 0 & 0 & 0 & 0 & 0 & 0 & 0 \\
\hline & $v_{\mathrm{ses}, \mathrm{NH} 4}$ & $v_{\text {ses, } \mathrm{NO} 3}$ & 0 & $-\lambda_{\text {ses }}$ & 0 & 0 & 0 & 0 & 0 & 0 & 0 & 0 & 0 & 0 \\
\hline & $v_{\mathrm{FBOM}, \mathrm{NH} 4}$ & $v_{\mathrm{FBOM}, \mathrm{NO} 3}$ & 0 & 0 & $-\lambda_{\mathrm{FBOM}}$ & 0 & 0 & 0 & 0 & 0 & 0 & 0 & 0 & 0 \\
\hline & $v_{\mathrm{CBOM}, \mathrm{NH} 4}$ & $v_{\mathrm{CBOM}, \mathrm{NO} 3}$ & 0 & 0 & 0 & $-\lambda_{\mathrm{CBOM}}$ & 0 & 0 & 0 & 0 & 0 & 0 & 0 & 0 \\
\hline & 0 & 0 & $v_{\mathrm{pet}, \mathrm{NO} 3}$ & 0 & 0 & 0 & $-\lambda_{\text {pet }}$ & 0 & 0 & 0 & 0 & 0 & 0 & 0 \\
\hline & 0 & 0 & $v_{\mathrm{pse}, \mathrm{NO} 3}$ & 0 & 0 & 0 & 0 & $-\lambda_{\text {pse }}$ & 0 & 0 & 0 & 0 & 0 & 0 \\
\hline & 0 & 0 & 0 & $v_{\text {lep,ses }}$ & 0 & 0 & 0 & 0 & $-\lambda_{\text {lep }}$ & 0 & 0 & 0 & 0 & 0 \\
\hline & 0 & 0 & 0 & 0 & $v_{\text {tri, } \mathrm{FBOM}}$ & 0 & 0 & 0 & 0 & $-\lambda_{\text {tri }}$ & 0 & 0 & 0 & 0 \\
\hline & 0 & 0 & 0 & 0 & 0 & $v_{\text {eud,CBOM }}$ & 0 & 0 & 0 & 0 & $-\lambda_{\text {eud }}$ & 0 & 0 & 0 \\
\hline & 0 & 0 & 0 & 0 & 0 & $v_{\text {phy, СBOM }}$ & 0 & 0 & 0 & 0 & 0 & $-\lambda_{\text {phy }}$ & 0 & 0 \\
\hline & 0 & 0 & 0 & 0 & 0 & 0 & 0 & 0 & $v_{\text {arg,lep }}$ & $v_{\text {arg,tri }}$ & 0 & 0 & $-\lambda_{\arg }$ & 0 \\
\hline & 0 & 0 & 0 & 0 & 0 & 0 & 0 & 0 & 0 & 0 & 0 & $v_{\text {eut,phy }}$ & 0 & $-\lambda_{\text {eut }}$ \\
\hline
\end{tabular}

Because the dynamics of the two inorganic element compartments, $\mathrm{NH}_{4}{ }^{+}$and $\mathrm{NO}_{3}{ }^{-}$, occur at much faster rates than the rest, the system can be numerically approximated by assuming that they are completely regenerated at each infinitesimal time step and driven by external inputsor, in other words, that they are completely replaced by the flux from upstream. Note that this assumption does not imply that the system modeled is completely open but is merely a mathematical simplification that treats water nutrient as a given in order to simplify the estimation. This can be mathematically expressed by setting $\psi_{1,1}=\psi_{2,2}=0$ and by replacing after each step of the numerical integration of the system of differential equations the elements $x_{1}$ and $x_{2}$ of $\mathbf{x}$ with values that reflect the measured profiles for $\mathrm{NH}_{4}{ }^{+}$and $\mathrm{NO}_{3}{ }^{-}$at sampling point $s$. In our example, we have three sampling points (transects) per stream.

Given this, we can model the two parallel subsystems comprising $\mathbf{x}$ : unmarked nutrient $\mathbf{n}$ and marked nutrient $\mathbf{m}$, representing the dynamics of each isotope. While both systems will be governed by the same transition matrix $\boldsymbol{\Psi}$, they have different initial values $\mathbf{n}^{(0)}$ and $\mathbf{m}^{(0)}$ corresponding to the background isotopic ratios before the drip experiment has started. The inorganic nutrient compartments also have different forced input profiles between unmarked and marked nutrient pools. The forced quantity of unmarked tracer in the inorganic compartments is constant through time, such that

$$
n_{i}^{(s, t)}={ }^{14} \mathrm{~N}_{i, \mathrm{bkg}}^{(s)} \quad \text { for } i \in \mathcal{I} \text { and all } t \text { values, }
$$

where $\mathcal{I}$ defines the set of inorganic nutrient compartments $\left(\mathrm{NH}_{4}{ }^{+}\right.$and $\left.\mathrm{NO}_{3}{ }^{-}\right)$and ${ }^{14} \mathrm{~N}_{i, \text { bkg }}^{(s)}$ is the natural (background) abundance of ${ }^{14} \mathrm{~N}\left(\mathrm{mgN} \mathrm{m}^{-2}\right)$ in the inorganic nutrient compartment $i$ measured at sampling transect $s$.
On the contrary, the forced quantity of marked nutrient in the inorganic compartments changes with the experimental enrichment profile. This means that if we define $t_{\text {off }}$ as the time the drip is turned off, then the following step function drives $m_{i}^{(s, t)}$ :

$m_{i}^{(s, t)}=\left\{\begin{array}{cl}{ }^{15} \mathrm{~N}_{i, \mathrm{bkg}}^{(s)}+{ }^{15} \mathrm{~N}_{i, \mathrm{add}}^{(s)} & \text { for } i \in \mathcal{I} \text { and } t<t_{\mathrm{off}}, \\ { }^{15} \mathrm{~N}_{i, \mathrm{bkg}}^{(s)} & \text { for } i \in \mathcal{I} \text { and } t \geq t_{\mathrm{off}} .\end{array}\right.$

Here, ${ }^{15} \mathrm{~N}_{i, \text { bkg }}^{(s)}$ represents the natural (background) abundance of the heavy isotope $\left({ }^{15} \mathrm{~N}\right)$ form of the inorganic nutrient compartment measured at sampling transect $s$ before nutrient addition, and ${ }^{15} \mathrm{~N}_{i, \text { add }}^{(s)}$ is the additional ${ }^{15} \mathrm{~N}$ measured during the experimental addition at sampling transect $s$.

We tested eight topological model structures of the network $\boldsymbol{\Psi}_{\mathrm{h}}$ representing the variations of $\boldsymbol{\Psi}_{111}$ where one or more of three uncertain links were eliminated. The uncertain links corresponded to the uptake of FBOM by the Eudaniela crabs and predation of Psephenus waterpennies and Petrophila caterpillars by Argia damselflies (table 2).

We fit the models to the data on Lower and Upper La Laja using transect- and compartment-specific time series of isotopic proportions $z_{\mathrm{obs}, i}^{(s, t)}$ as well as compartment-specific biomass data $x_{\mathrm{obs}, i}^{(s, t)}$ at three points in time $t$ and three points in space $s$. Latent biomasses $x_{i}$ were assumed to be constant (i.e., at steady state); therefore, sample differences were considered to be random with observed standard deviation $\mathrm{SD}_{i}$. In practice, this allows for deviations of the steady-state assumption that are within the range of the compartment's natural variation.

We fit the model in R version 3.6 (R Core Team 2019) by implementing it in Stan (Carpenter et al. 2017) and running it with the RStan package (Stan Development Team 2019). Details on the model implementation and of the 
Table 2: Comparison of alternative models of food web structure regarding Argia and Eudaniela diets

\begin{tabular}{lccccccc}
\hline & \multicolumn{5}{c}{ Trophic link } & & \\
Model & Petrophila $\rightarrow$ Argia & Psephenus $\rightarrow$ Argia & FBOM $\rightarrow$ Eudaniella & No. parameters & DIC & $\Delta$ DIC & $w_{\text {DIC }}$ \\
\hline $\boldsymbol{\Psi}_{100}$ & Yes & No & No & 68 & $-2,844.8$ & 0 & .757 \\
$\boldsymbol{\Psi}_{110}$ & Yes & Yes & No & 70 & $-2,841.5$ & 3.3 & .146 \\
$\boldsymbol{\Psi}_{000}$ & No & No & No & 66 & $-2,839.3$ & 5.4 & .05 \\
$\boldsymbol{\Psi}_{010}$ & No & Yes & No & 68 & $-2,839.1$ & 5.6 & .046 \\
$\boldsymbol{\Psi}_{111}$ & Yes & Yes & Yes & 72 & $-2,830$ & 14.8 & 0 \\
$\boldsymbol{\Psi}_{011}$ & No & Yes & Yes & 70 & $-2,828.2$ & 16.6 & 0 \\
$\boldsymbol{\Psi}_{101}$ & Yes & No & Yes & 70 & $-2,823.9$ & 20.8 & 0 \\
$\boldsymbol{\Psi}_{001}$ & No & No & Yes & 68 & $-2,810.5$ & 34.2 & 0 \\
\hline
\end{tabular}

Note: DIC = deviance information criterion; FBOM = fine benthic organic matter.

priors used are described in supplementary material S1 (supplementary materials S1, S2 are available online). The data and the source code used in our study can be found as an $\mathrm{R}$ package in the Dryad Digital Repository (https:// doi.org/10.5061/dryad.8sf7m0chx; López-Sepulcre et al. 2020).

We assumed that both streams have the same network topology of trophic links, albeit with different parameter values. We therefore calculated the joint DIC for both streams by adding the DICs of the same model fit to the two streams. We chose the best model as the one with the lowest joint DIC.

\section{Calculation of Derived Parameters}

After selecting the best model, we illustrate the calculation of some important derived metrics, their uncertainty, and their comparison between the natural (LL) and open canopy (UL) streams. To do so, one only has to apply the required calculation with all 1,000 sampled values of the MCMC chain rather than with the estimates of the parameters. This produces a probability distribution for the derived parameter, which can be used to calculate measures of dispersion, such as standard errors or 95\% quantiles (i.e., credible intervals).

A common quantity of interest is the expected residence or turnover time $T_{j}$ of nutrient $\mathrm{N}$ in each compartment $j$, which can be calculated as the inverse of the turnover rate:

$$
T_{j}=\frac{1}{k_{j}}=\frac{1}{\lambda_{j}+\sum_{i=1}^{C} v_{i, j}} .
$$

In the case of compartments divided into active and refractory subcompartments, the apparent residence time $T_{j}^{\prime}$ will be larger:

$$
T_{j}^{\prime}=\frac{1}{\pi_{j} k_{j}}=\frac{1}{\pi_{j}\left(\lambda_{j}+\sum_{i=1}^{C} v_{i, j}\right)}=\frac{T_{j}}{\pi_{j}} .
$$

The flux rates between compartments can be calculated as

$$
F_{i, j}=v_{i, j} \hat{X}_{j},
$$

where $F_{i, j}$ represents the flux from compartment $j$ to compartment $i$ and $\hat{X}_{j}$ is the expected biomass. Because we assume the system to be at steady state, expected biomasses can be calculated using an eigenanalysis of the system as follows. Under steady state, the two nutrient forms $\mathrm{NH}_{4}{ }^{+}$ and $\mathrm{NO}_{3}{ }^{-}$ought to remain constant, which we can achieve by defining a transfer matrix $\boldsymbol{\Psi}^{\prime}$ that equals $\boldsymbol{\Psi}$ but with $\psi_{1,1}^{\prime}=\psi_{2,2}^{\prime}=1$ and $\psi_{i, i}^{\prime}=1-k_{i}$ for the other compartments. This matrix will have at least two right eigenvectors $\mathbf{v}^{(\mathrm{NH4})}$ and $\mathbf{v}^{(\mathrm{NO3})}$ corresponding to an eigenvalue of 1 , which are scaled to a norm of 1 . The elements $i$ of each of these $14 \times 1$ vectors represent the relative equilibrium biomass of compartment $i$ that originates from each of the two inorganic nutrients, $\mathrm{NH}_{4}{ }^{+}$and $\mathrm{NO}_{3}{ }^{-}$, respectively. Because the eigenvectors $\mathbf{v}^{(\mathrm{NH} 4)}$ and $\mathbf{v}^{(\mathrm{NO})}$ are scaled to a norm of 1 , they need to be rescaled on the basis of the mass of $\mathrm{NH}_{4}{ }^{+}$and $\mathrm{NO}_{3}{ }^{-}$in the water, respectively. The total equilibrium biomass $\hat{X}_{i}$ of compartment $i$ at steady state can thus be calculated as the sum elements $i$ of the two rescaled vectors as follows:

$$
\hat{X}_{i}=x_{1} \frac{v_{i}^{(\mathrm{NH} 4)}}{v_{1}^{(\mathrm{NH} 4)}}+x_{2} \frac{v_{i}^{(\mathrm{NO} 3)}}{v_{2}^{(\mathrm{NO} 3)}},
$$

where $x_{1}$ and $x_{2}$ are the background masses $\left(\mathrm{mgN} \mathrm{m}^{-2}\right)$ of $\mathrm{NH}_{4}{ }^{+}$and $\mathrm{NO}_{3}{ }^{-}$in the stream. It is worth noting that at steady state, it should be true that inputs should equal outputs, and therefore

$$
F_{i, .}=k_{i} \cdot \hat{X}_{i} \Leftrightarrow \hat{X}_{i}=F_{i, .} \cdot T_{i},
$$

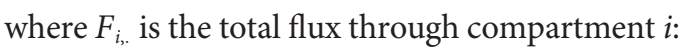

$$
F_{i, .}=\sum_{j=1}^{C} F_{i, j} \hat{X}_{j}
$$


The total flux of $\mathrm{N}$ through the system can then be calculated as the sum of fluxes from the set of nutrient input compartments $\mathcal{I}$ (in our case, $\mathrm{NH}_{4}{ }^{+}$and $\mathrm{NO}_{3}{ }^{-}$) to the set of basal compartments $\mathcal{B}$ (in our case, epilithon, seston, FBOM, and CBOM):

$$
F_{T}=\sum_{j \in \mathcal{I}} \sum_{i \in \mathcal{B}} F_{i, j}
$$

Total flux is of interest as an indicator of wholeecosystem productivity, and we expect it to be higher under higher light conditions (i.e., in Upper La Laja). A second metric of interest is the relative use of $\mathrm{NO}_{3}{ }^{-}$compared with $\mathrm{NH}_{4}^{+}$by primary producers. Primary producers favor $\mathrm{NH}_{4}{ }^{+}$over $\mathrm{NO}_{3}{ }^{-}$, as a result of lower assimilation cost (Morris 1974). Because more productive streams have higher demand of $\mathrm{N}$ and greater energy supply, we expect primary producers in the high light stream to supplement their $\mathrm{N}$ need by assimilating nitrate and therefore have a higher ratio of $\mathrm{NO}_{3}{ }^{-}$flux to $\mathrm{NH}_{4}{ }^{+}$(Morris 1974). The proportion of $\mathrm{N}$ uptake flux into a given consumer compartment $i$ coming from a given source compartment $j$ can be calculated as

$$
P_{i, j}^{U}=\frac{v_{i, j} x_{j}}{\sum_{r=1}^{C} v_{i, r} x_{r}} .
$$

We will calculate the proportional use of $\mathrm{NO}_{3}{ }^{-}$by epilithon $\left(P_{\mathrm{epi} \text { NO3 }}^{U}\right)$ to test the above-described hypothesis of preferential $\mathrm{NH}_{4}{ }^{+}$use under light limitation. Note that this can also be expressed as a ratio of $\mathrm{NO}_{3}{ }^{-}$to $\mathrm{NH}_{4}{ }^{+}$use:

$$
R_{\mathrm{epi}, \mathrm{NO} 3}=\frac{P_{\mathrm{epi}, \mathrm{NO} 3}^{U}}{1-P_{\mathrm{epi}, \mathrm{NO} 3}^{U}} .
$$

Similarly, one can use $P_{i, j}^{U}$ to evaluate the importance of a particular compartment in the diet of a consumer. We illustrate this by calculating the importance of Petrophila water moths in the diet of Argia damselflies $P_{\text {arg,pet }}^{U}$.

Conversely, we can calculate the contribution of a particular consumer $i$ to the turnover of a given resource compartment $j$ as

$$
P_{i, j}^{K}=\frac{v_{i, j}}{k_{j}}=\frac{v_{i, j}}{\lambda_{j}+\sum_{r=1}^{C} v_{r, j}} .
$$

As an example, we calculate the contribution of Eudaniela crabs to the turnover of CBOM, $P_{\text {eud, Свом }}^{K}$.

\section{Derived Parameter Uncertainty and Statistical Comparisons}

One of the main advantages of Bayesian inference though MCMC is that it is straightforward to carry out the estima- tion error on the primary parameters onto the derived parameters. This is done by simply applying the relevant calculation elementwise on the MCMC chains of the estimated parameters. This results in a posterior distribution of the derived parameter that naturally accounts for the error in all its component parameters. One can then calculate from the posterior distribution any relevant measure of uncertainty (e.g., standard error or credible intervals).

In the same manner, one can compare the parameter estimates between two streams by simply calculating the elementwise difference (or ratio, or any other measure of effect size) in the MCMC chains. A Bayesian posterior predictive $P$ value for the difference can then be extracted by calculating the proportion of the posterior distribution that falls below zero (or 1, in the case of a ratio).

\section{Results}

The most parsimonious network topology corresponded to model $\boldsymbol{\Psi}_{100}$, which includes the consumption of Petrophila by Argia but not consumption of Psephenus by Argia nor FBOM by Eudaniela crabs (table 2). The second-best model was 3.3 DIC units away, indicating moderate support for the best model. However, the overall support for a Petrophila $\rightarrow$ Argia link is higher if we consider all tested models. The sum of the DIC weights of all of the models including that link is 0.90 (out of 1), compared with only 0.19 for a Psephenus $\rightarrow$ Argia link and $<0.01$ for an FBOM $\rightarrow$ Eudaniela link. We therefore present the results for model $\boldsymbol{\Psi}_{100}$. Figure 2 shows the fit for isotope ratios for this model in both streams for the first transects (see fig. S1 for all transects and fig. S2 for biomass fit; figs. S1-S3 are available online), while the parameter estimates, credible intervals, MCMC chains, and posterior distributions can be found in table $\mathrm{S} 1$ and fig. S3).

To compare our proposed approach to current standard methodology, in figure 3 we compare our estimates of compartment fluxes and turnover times with estimates obtained in a previous analysis of the same data (Collins et al. 2016), using current methodology (Dodds et al. 2000). For basal compartments that are split into an active portion $\pi_{i}$ and a refractory portion $1-\pi_{i}$, apparent turnover times $T_{i}^{\prime}$ in our analyses (eq. [22]) are equivalent to the turnover times estimated in Collins et al. (2016). Fourteen of the 24 compartment uptake rates estimated by Collins et al. lie within the $95 \%$ credible intervals of our estimates, as 14 of the 24 turnover time estimates do. Relative to the estimates derived by our model, the estimates of Collins et al. tend to overestimate uptake in the basal compartments and underestimate it for some consumers, while the converse is true for turnover time. Differences between 

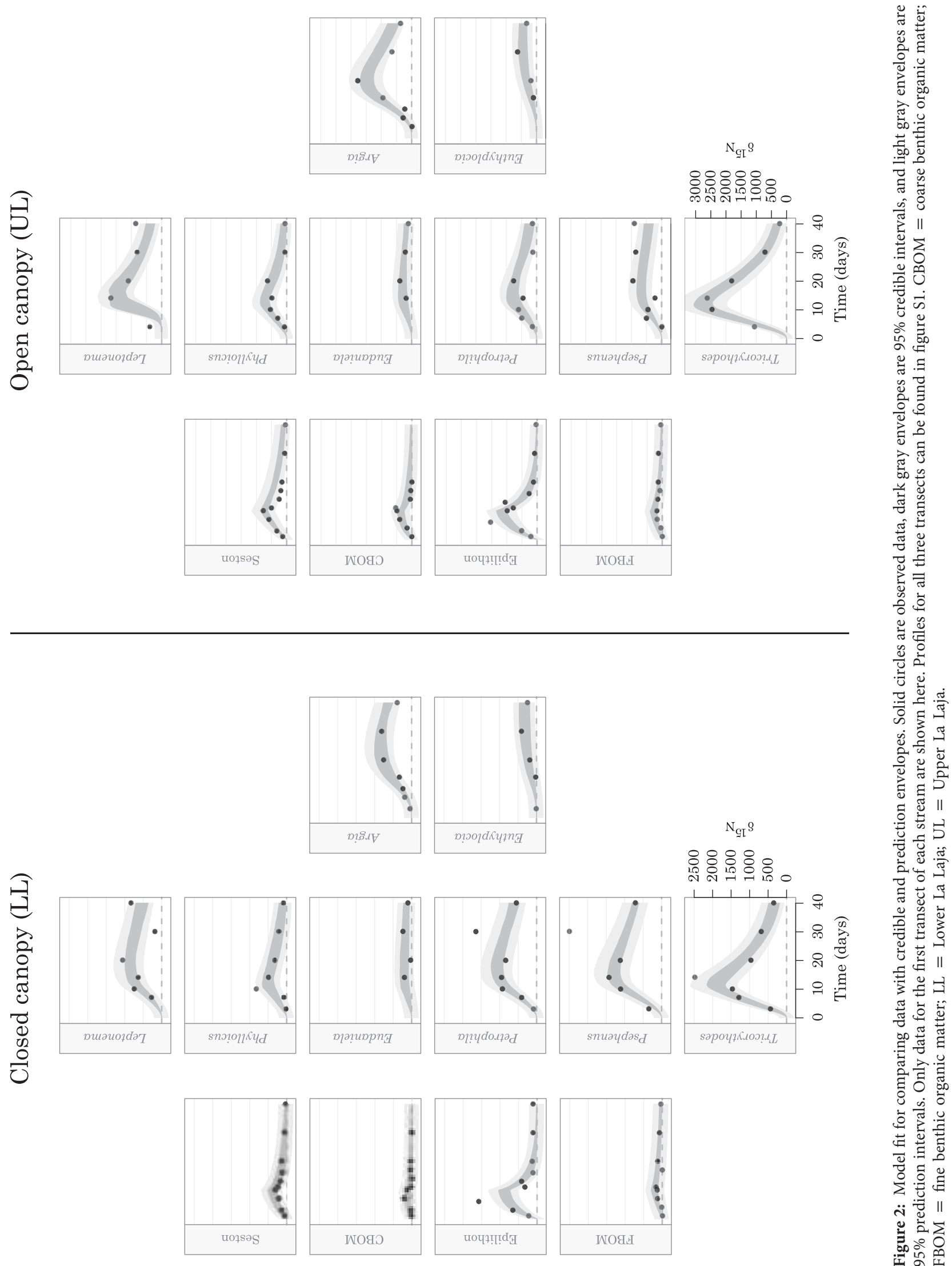


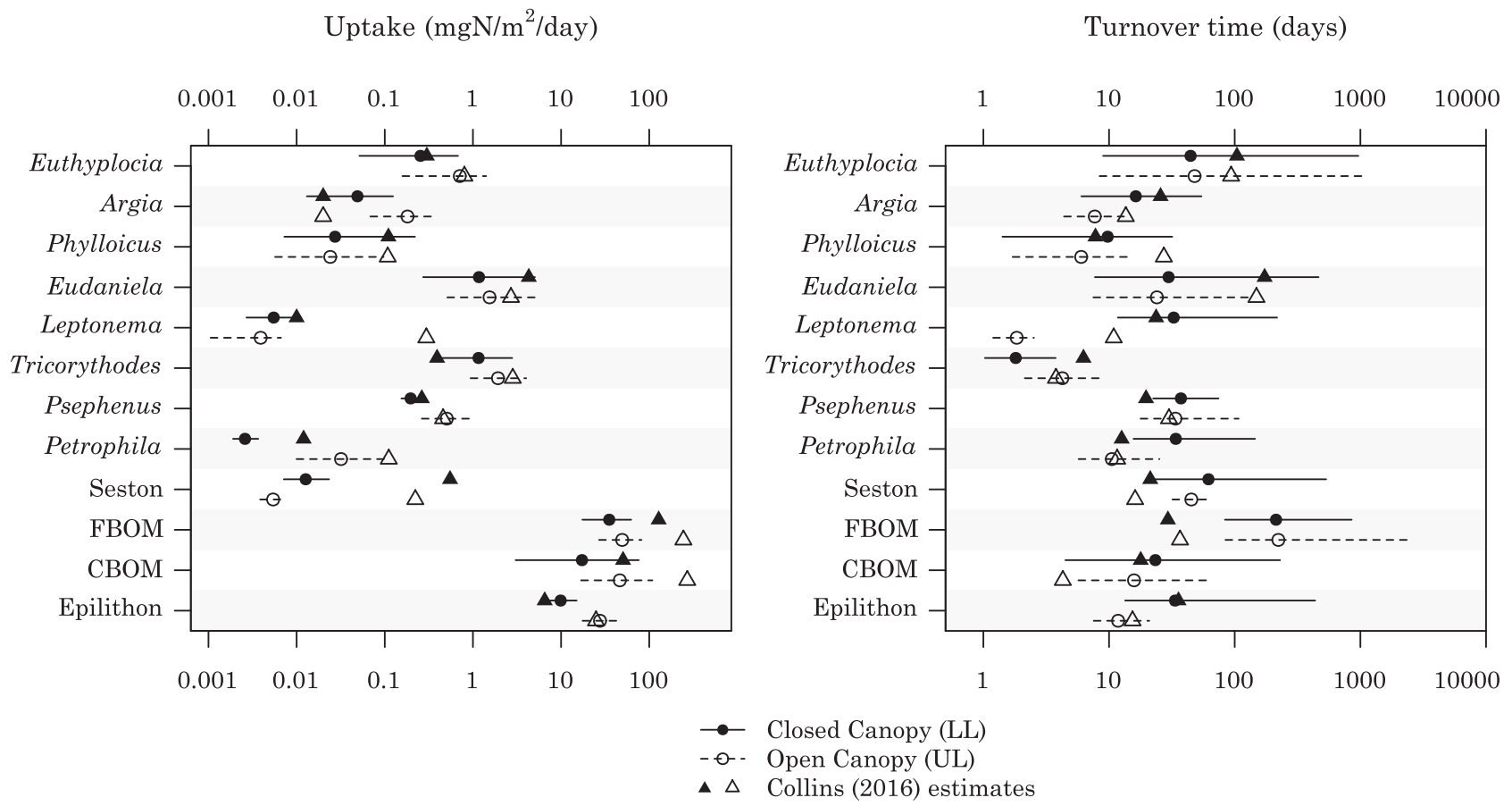

Figure 3: Estimates of uptake fluxes and turnover times of all compartments for Lower La Laja (LL; solid symbols) and Upper La Laja (UL; open symbols). Circles and error bars represent our estimates and $95 \%$ credible intervals. Triangles represent the estimates made by Collins et al. (2016). Turnover was not estimated for Argia or Euthyplocia in Collins et al. (2016). Note that the axis scale is logarithmic. CBOM = coarse benthic organic matter; $\mathrm{FBOM}=$ fine benthic organic matter.

methods in estimates were often not trivial and in some cases varied by an order of magnitude (e.g., CBOM uptake or Eudaniela turnover). The negative relationship between the bias of uptake and turnover time is expected, given that an overestimate of uptake must be balanced by decreased turnover time in order to explain the same concentration of tracer in a given compartment.

The estimates and 95\% credible intervals of all fluxes among compartments, turnover times, and expected steadystate biomasses are found in supplementary material S2 (tables S2, S3) and represented in figure 4. This figure summarizes the three main aspects of nitrogen dynamics across compartments: fluxes between compartments, turnover (or residence) times, and compartment biomasses. Basal compartments are divided into their active (solid white) and refractory (hatched) portions as estimated by $\pi_{i}$, with $T_{i}$ and $T_{i}^{\prime}$ represented by the width of the white solid portion of the box and the total width of the box, respectively. As expected, active portions of basal compartments tend to be larger in the open canopy stream than the closed canopy stream, particularly for epilithon $\left(\left(\pi_{\text {epi }}\right)^{\mathrm{LL}}=0.13 \pm 0.07\right.$, $\left.\left(\pi_{\text {epi }}\right)^{\mathrm{UL}}=0.44 \pm 0.12\right)$ and $\mathrm{CBOM}\left(\left(\pi_{\mathrm{CBOM}}\right)^{\mathrm{LL}}=0.30 \pm\right.$ $0.14,\left(\pi_{\mathrm{CBOM}}\right)^{\mathrm{UL}}=0.50 \pm 0.13$; values given as mean $\pm \mathrm{SD}$; table S1). Another clear and expected pattern that emerges from figure 4 is the overall higher fluxes into the basal compartments in the open canopy stream. This is illustrated in figure 5 and is in good part due to an increased $\mathrm{NO}_{3}{ }^{-}$uptake by epilithon and CBOM. In contrast, the increase in $\mathrm{N}$ uptake by FBOM is mostly due to increased $\mathrm{NH}_{4}{ }^{+}$uptake.

A consistent pattern across our analyses was the high uncertainty associated with estimates of fluxes, turnover, and other derived parameters. Despite this quantitative uncertainty, it is possible to make important statistical inferences regarding differences among compartments and between streams. Total flux is higher in the open canopy than the closed canopy stream $\left(\left(F_{T}\right)^{\mathrm{UL}}-\left(F_{T}\right)^{\mathrm{LL}}=63.7 \pm 35.9\right.$, one-sided Bayesian $P=.036$; fig. $6 A)$, and epilithon's uptake shows a higher ratio of $\mathrm{NO}_{3}{ }^{-}$to $\mathrm{NH}_{4}{ }^{+}$uptake $\left(\log \left[\left(R_{\text {epi,NO3 }}\right)^{\mathrm{UL}}\right]-\log \left[\left(R_{\text {epi,NO3 }}\right)^{\mathrm{LL}}\right]=3.54 \pm 1.51 ; P=\right.$ .008 , fig. $6 B)$, as expected. Although there seems to be a higher contribution of Eudaniela crabs to CBOM turnover in the closed canopy stream, the parameters around Eudaniela are highly uncertain due to irregular sampling (crab captures are patchy), and this difference is not significant $\left(\operatorname{logit}\left[\left(P_{\text {eud,CBOM }}^{\mathrm{K}}\right)^{\mathrm{UL}}\right]-\operatorname{logit}\left[\left(P_{\text {eud,CBOM }}^{\mathrm{K}}\right)^{\mathrm{LL}}\right]=-1.02 \pm 1.74\right.$; $P=.28$; fig. $6 C)$. A clearer but still nonsignificant result is that Petrophila moths seem to represent a higher proportion of the diet of Argia damselflies in our high light stream 

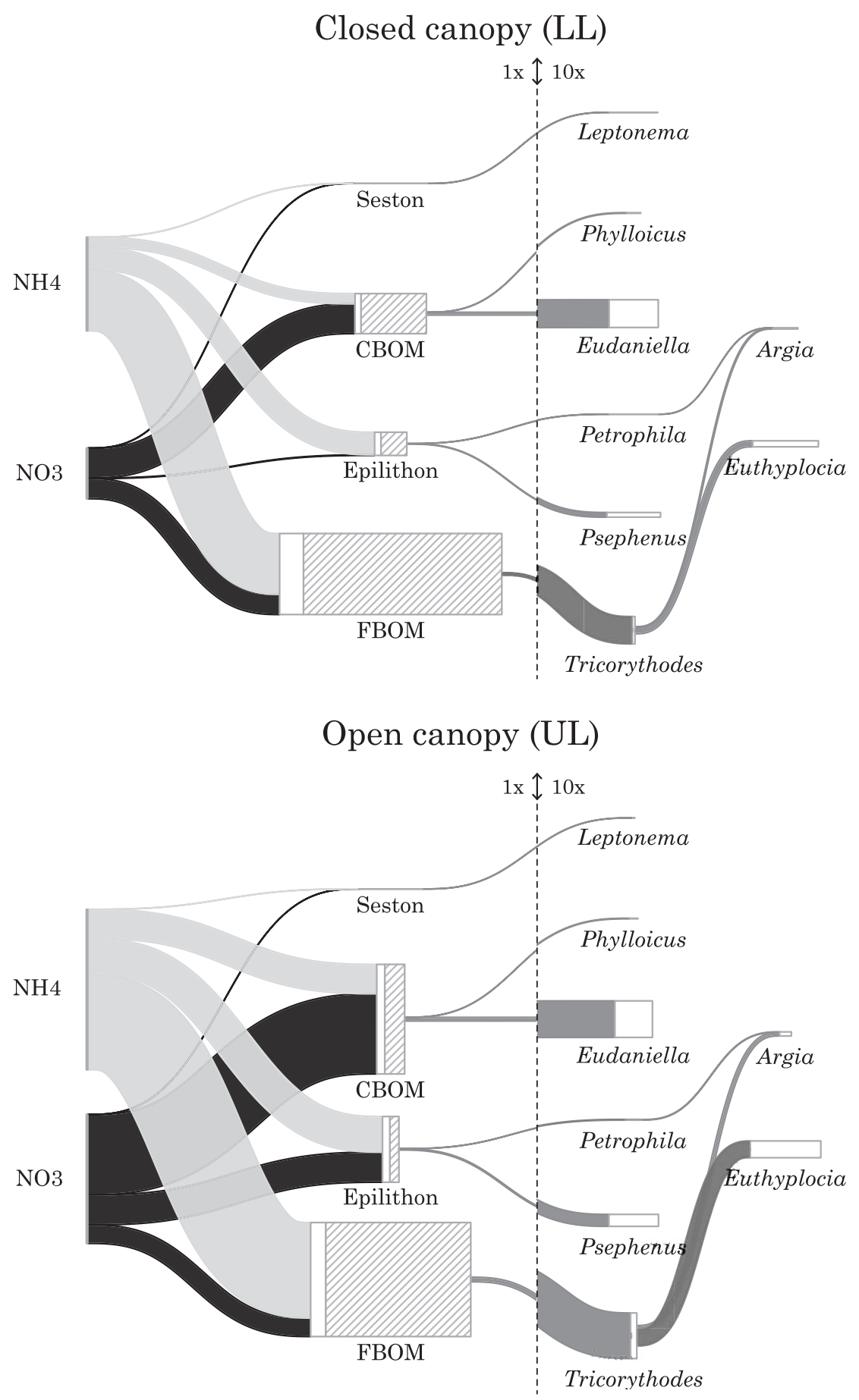

Figure 4: Quantitative food web reconstruction of the two streams. Compartments are represented by boxes, and fluxes between them are represented by filled curved lines connecting them. The white box area represents the active portion of the compartment $\pi_{i}$, while the gray hatched area on the basal compartments represents the nonactive (refractory) proportion $\left(1-\pi_{i}\right)$. Curve thickness is proportional to the flux rate calculated following equation (23). The height of all nonnutrient compartment boxes is therefore proportional to the total uptake of $\mathrm{N}$ by that compartment. Box widths of nonnutrient compartments are proportional to the compartment's turnover time, with the width of the white area representing the turnover time of the active component and the total width representing the overall turnover time. The area of the box is therefore proportional to the compartment's biomass under the steady-state assumption (as per eq. [25]). Note that the fluxes and biomasses have been magnified by $\times 10$ on the right side of the figure in order to visualize differences between streams. $\mathrm{CBOM}=$ coarse benthic organic matter; FBOM = fine benthic organic matter; LL = Lower La Laja; UL = Upper La Laja. 


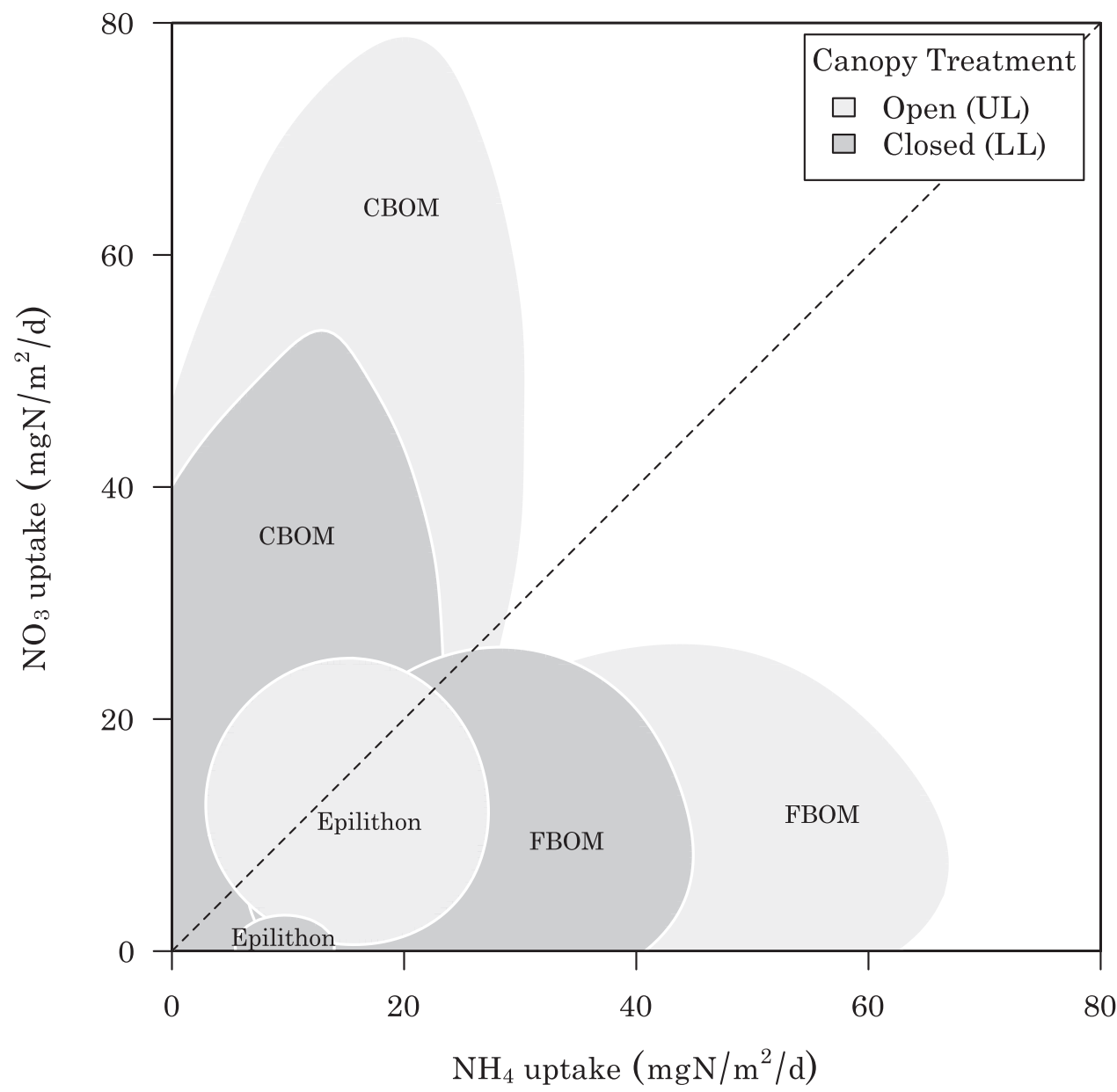

Figure 5: Distribution of total $\mathrm{NH}_{4}{ }^{+}$and $\mathrm{NO}_{3}{ }^{-}$uptake among the three main basal compartments. Gray areas represent $95 \%$ credible bounds. The dashed isoline indicates equal uptake of $\mathrm{NH}_{4}{ }^{+}$and $\mathrm{NO}_{3}{ }^{-}$, with estimates above it indicating a dominance of $\mathrm{NO}_{3}{ }^{-}$uptake over $\mathrm{NH}_{4}{ }^{+}$. Estimated values can be seen in table S3. Seston uptake is not visible because it is very close to zero and has small credible bounds. $\mathrm{CBOM}=$ coarse benthic organic matter; FBOM = fine benthic organic matter; LL = Lower La Laja; UL = Upper La Laja.

$\left(\mathrm{UL}>\mathrm{LL}, \operatorname{logit}\left[\left(P_{\text {arg.pet }}^{\mathrm{U}}\right)^{\mathrm{UL}}\right]-\operatorname{logit}\left[\left(P_{\text {arg.pet }}^{\mathrm{U}}\right)^{\mathrm{LL}}\right]\right)=1.48 \pm$ $1.43 ; P=.13$; fig. $6 D)$.

\section{Discussion}

We have presented a statistical formalization of a tracer addition to track nutrient movement through an ecosystem. As such, this is the first evaluation of the uncertainty involved in the estimation of uptake and turnover using these experiments. Quantifying and managing such uncertainty is important in these experiments because of the limited amount of data involved and because they measure phenomena that propagate across scales. Beyond accounting for sampling error, our method can handle three important sources of error or bias that were previously suboptimally handled. First, modeling the system as a whole ensures that the interdependence of parameter estimates among com- partments becomes explicit, and thus the error in the estimates of nitrogen dynamics of a particular compartment is incorporated in the estimation of the compartments that consume it. In the past, this kind of error propagation has been ignored (Dodds et al. 2000). Second, it is now possible to model diet uncertainty at two levels: topological and quantitative. By topological uncertainty we refer to the uncertainty regarding the presence or absence of a particular trophic link. By modifying the topology of the transfer matrix $\boldsymbol{\Psi}$ (i.e., changing which of its elements $\psi_{i, j}$ are different from zero), one can explicitly test different hypotheses regarding the trophic structure of the ecosystem using model selection techniques and either select the best model or average across models using model averaging. We have illustrated how to do so using the DIC (Spiegelhalter et al. 2002), but other Bayesian techniques, such as reversiblejump MCMC (Green 1995) or variable selection methods, 


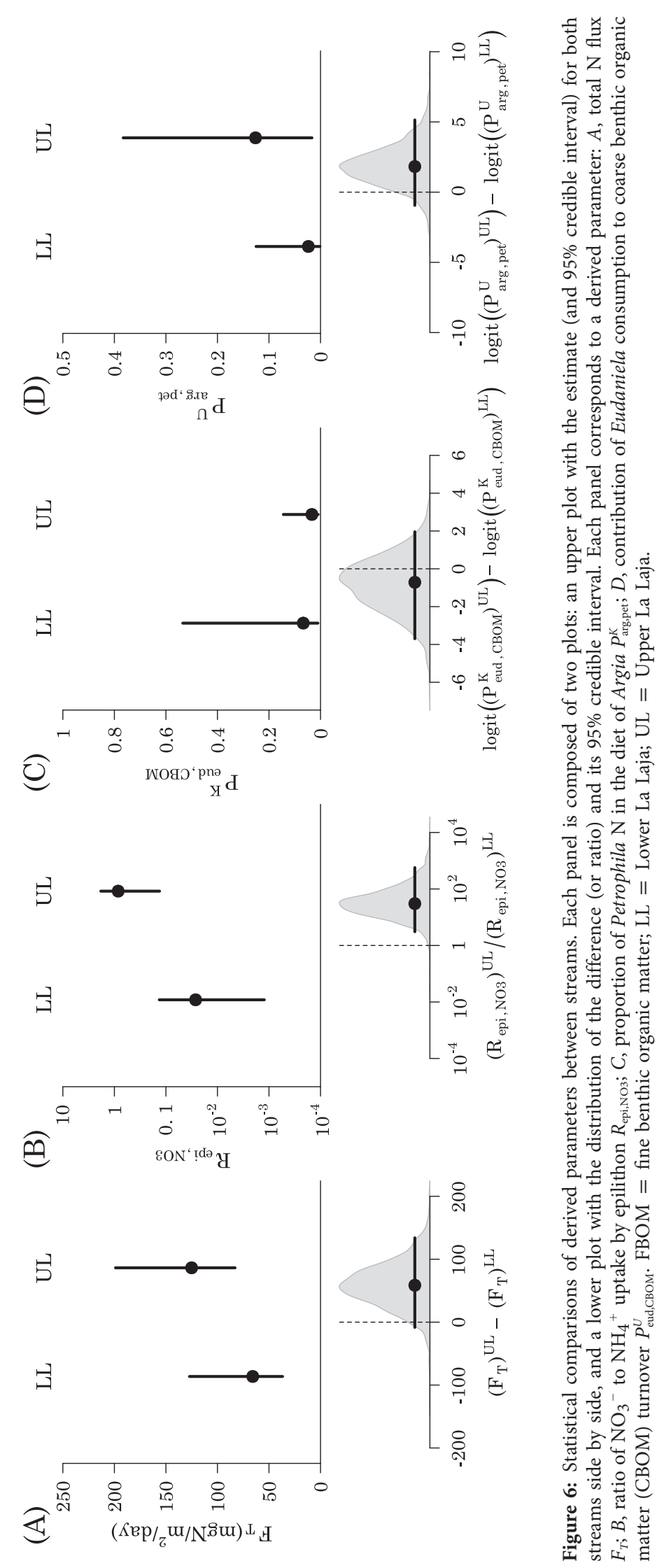


can be implemented (for reviews on available methods, see Tenan et al. 2014; Hooten and Hobbs 2015). By quantitative uncertainty we refer to the diet of organisms with more than one food source. Past models required the input of assumed proportions of each source. This is not necessary in our approach, and the proportion of each resource consumed (and its uncertainty) can be calculated as a derived parameter after the model fit (see eq. [29]). Finally, our method offers a solution to the paradox of overenrichment, whereby consumer compartments appear more labeled than their sources (Dodds et al. 2014). It does so by allowing the partitioning of resource compartments into an active portion $\pi_{i}$ that uptakes detectable marked nutrient during the time frame of the experiment and a refractory one that does not (or does so at much larger timescales). Because this portion is an estimated parameter, its uncertainty is evaluated, which is an advantage over the post hoc multiplicative factor approach previously proposed (Dodds et al. 2014).

All of the above-mentioned sources of uncertainty get integrated to produce the uncertainty in the posterior distribution of the evaluated parameters. As exemplified by our case study, this uncertainty can sometimes be rather large, which is not surprising given the typically high dimensionality of these systems and the limited amount of data (due to the high cost of isotopic analysis and the need to minimize invasiveness). This highlights further the importance of measuring and reporting the uncertainty in the estimated parameters in order to temper our statements on the results. One of the advantages of our Bayesian implementation is that it can incorporate prior knowledge to help reduce this uncertainty, a strategy increasingly used in ecological management (McCarthy and Masters 2005). This can be in the form of supplementary experiments on specific organisms or published values on similar taxa and systems. Moreover, it is possible to evaluate the influence of prior information using prior sensitivity analysis and therefore formally evaluate the contribution of our data to the increase (or decrease) of certainty in the studied parameters. Ultimately, our method can be used on simulated data prior to an experiment in order to test the power of alternative experimental designs regarding the dripping regime and the sampling schedule of each compartment. In our opinion, this is one of the most powerful advantages of having a formal statistical framework available for isotope tracer experiments. While a full exploration of different designs is beyond the scope of this article, two important aspects of the design that are important to parameter identifiability seem apparent to us. First, it is necessary to have good temporal resolution of samples where uptake of tracer changes slope significantly (e.g., at peak uptake). Second, if more than one nutrient is labeled (as is the case here with both forms of nitrogen), it is important that their labeling is not strongly positively correlated if one is to dis- tinguish differential uptake of each source. In our example, the dynamics of nitrification ensure that as ${ }^{15} \mathrm{NH}_{4}{ }^{+}$label decreases downstream, ${ }^{15} \mathrm{NO}_{3}{ }^{-}$increases, allowing us to tease apart ${ }^{15} \mathrm{NH}_{4}{ }^{+}$from ${ }^{15} \mathrm{NO}_{3}{ }^{-}$uptake.

Despite large uncertainties around some parameter values, we were able to identify some important expected differences in the functioning of the two study streams. For example, basal (and total fluxes) are higher in the open canopy stream (fig. 6A), as expected by the limiting effect of light in forested streams (Vannote et al. 1980). This result is consistent with previous analyses (Collins et al. 2016) and with other contemporary work at the same study sites that show an increase in chlorophyll $a$ abundance with light (Kohler et al. 2012) and increased gross primary production in the open canopy stream (A. O. H. C. Leduc, S. A. Thomas, A. López-Sepulcre, et al., unpublished manuscript). Our analysis also clearly shows a higher ratio of $\mathrm{NO}_{3}{ }^{-}$to $\mathrm{NH}_{4}{ }^{+}$use by epilithon in the open canopy stream (fig. 6B). This is consistent with the fact that $\mathrm{NH}_{4}{ }^{+}$is the preferred form of nitrogen to algae, and as light increases the higher nutrient demand drives algae to use other sources of nitrogen, such as $\mathrm{NO}_{3}{ }^{-}$(Morris 1974).

Our analysis also suggests potential biases in previous estimation methods that approximate postdrip ${ }^{15} \mathrm{~N}$ turnover by fitting an exponential decay curve (Collins et al. 2016). Previous estimates show higher consumer turnover times than our statistical implementation and, consequently, higher uptake rates too (in order to maintain the same observed ${ }^{15} \mathrm{~N}$ concentration). This could be due to the increasing difficulty of detecting a clear exponential decrease in the isotopic ratio with increasing trophic level. The converse pattern is true for basal compartments: our approach estimates higher turnover times and higher uptake rates than Collins et al. (2016). This may be a consequence of our splitting of basal compartments in active and refractory portions. In Collins et al. (2016) primary consumers need to eat a larger quantity of their resource to get enough ${ }^{15} \mathrm{~N}$ signal, while in our model they need to eat a lower biomass of the active portion, which has higher ${ }^{15} \mathrm{~N}$ concentration. Less consumption should result in lower turnover rates and higher turnover times. A full investigation of the potential biases of the different methods will require an intensive simulation approach.

Through our model selection exercise, we were also able to contrast some of the topological assumptions of Collins et al. (2016). While Collins et al. assumed that Eudaniela crabs consume comparable amounts of CBOM and FBOM, our model selection exercise shows clear evidence against the consumption of FBOM. On the other hand, while in Collins et al. we assume that Argia damselflies only consume Tricorythodes mayflies, we found evidence in favor of them also preying on Petrophila larvae. This illustrates the power and importance of being able to perform model 
selection on isotope tracer experiments. Against a priori expectations, some of the untested links appear very weak (e.g., consumption of Petrophila by Argia). The purpose of our model comparison was illustrative, and a thorough examination of all trophic links is beyond the scope of our article, but we hope it is clear how this would be a straightforward exercise. We must caution, however, that the number of models increases exponentially with every link tested, and one must be wary of the risks of data dredging and overanalysis that come with testing too many models if there are no a priori reasons to test them all.

For all their advantages, from error propagation to the use of prior information, Bayesian models do have a main inconvenience: computing time. It took on average $4 \mathrm{~h}$ of computation to fit a single model to one stream, using parallel computing of the four MCMC chains on an Intel Core i5 processor (4590, $3.3 \mathrm{GHz})$ and $8 \mathrm{~GB}$ of RAM. Given that one of the strongest motivations to use this method is the need to statistically analyze the increasing number of large comparative studies (Mulholland et al. 2008; Norman et al. 2017; Tank et al. 2018), this is an important concern. However, faster computers and large clusters are likely to reduce these times quickly. It is also important to be aware of the method's limitations and simplifications. First, our model is based on a linear Markov process, which means that all transfer rates are a constant proportion of resource abundance. Strictly speaking, this is not a realistic assumption, since algal uptake often follow a nonlinear function of nutrient availability, such as Michaelis-Menten dynamics (O’Brien 1974), and consumers show saturating functional responses to prey abundance (Jeschke et al. 2002). However, this simplification, common in previous methods, is easily justified given the relatively short timeframe of isotope tracer addition experiments. This makes it unlikely that resource abundance will vary to the point that nonlinearities cannot be approximated locally by linear functions. In fact, our methods assumes that the system is approximately at steady state, meaning that there are no major changes in the biomass of compartments during the period of the study. It is possible that this assumption will not hold for some longer experiments in highly productive environments, and future developments of the model may alleviate this assumption using time series of biomass data throughout the experiment.

We can think of other aspects that can be incorporated into this framework in the future other than nonlinear uptake and growth dynamics. For example, this model could incorporate the longitudinal dimension explicitly, as was done in Newbold et al. (1983). In that effort, the water column was treated as a dynamic compartment and included particle exchange between the bed and the water column (the latter being critical to fitting the dynamics of the netspinning caddisfly). The present article, by contrast, is not spatially explicit, replaces the water column dynamics with external forcing, and neglects particle suspension, transport, and deposition. An explicit treatment of flow and longitudinal linkage would allow one to combine the temporal and spatial information of tracer distribution along the stream in order to increase the accuracy of our estimates of uptake and turnover. This can be particularly powerful for understanding the dynamics of nutrient pools and basal compartments (e.g., nitrification), whose faster dynamics makes tracer differences most apparent along the spatial axis (Mulholland et al. 2000; Peterson et al. 2001). A second potential development is the incorporation of nutrient cycling in the form of excretion or decomposition. This would essentially involve a new set of parameters $\rho_{i}$ denoting the recycling rate of compartment $i$ (i.e., the proportion of that compartment that returns to the $\mathrm{NH}_{4}^{+}$ pool). These parameters would populate the first row of the transfer matrix $\boldsymbol{\Psi}$. For compartment-specific recycling rates to be identifiable, however, they would likely require the incorporation of priors (e.g., using supplementary excretion trials) and the incorporation of the spatial scale proposed above.

Another possible development would be the integration of generalized linear mixed models (Bolker et al. 2009) or other models that allow for covariates to affect uptake and turnover rates. This would be particularly powerful in comparative analyses across different experiments and sites, as it would improve our ability to explicitly test effects of a particular variable of interest (e.g., light, temperature, or time) across streams or treatments.

In conclusion, we have presented a method that improves the statistical rigor of tracer addition analyses. Our hope is that it will not only be of great use as it stands but also provide a baseline template for further developments and improvements that extract the most information from such elegant experiments. Most importantly, our modeling approach allows statistical comparisons among systems and treatments as well as formal testing of alternative hypotheses, expanding the utility of isotope tracer experiments in comparative and experimental settings.

\section{Acknowledgments}

We thank D. L. DeAngelis, G. García-Costoya, S. De Bona, S. P. Gordon, S. Lambert, A. E. G. Lee, and K. Sidhu for fruitful discussions and comments on the manuscript. T. Heatherly, K. L. McNeill, and A. O. H. Leduc helped with different aspects of the tracer addition experiment. D. N. Reznick provided logistic support, infrastructure, and intellectual feedback throughout the performance of the tracer experiment. Funding was provided by grants from the Academy of Finland (295941) to A.L.-S. and a Frontiers in Integrative Biological Research (FIBR) grant 
from the National Science Foundation (EF0623632) to A.S.F. and S.A.T.

\section{Literature Cited}

Ainsworth, C. H., I. C. Kaplan, P. S. Levin, and M. Mangel. 2010. A statistical approach for estimating fish diet compositions from multiple data sources: Gulf of California case study. Ecological Applications 20:2188-2202.

Ball, R. C., and F. F. Hooper. 1963. Translocation of phosphorus in a trout stream ecosystem. Pages $217-228$ in V. Schultz and A. W. Klement Jr., eds. Radioecology. Reinhold, New York.

Banašek-Richter, C., M.-F. Cattin, and L.-F. Bersier. 2004. Sampling effects and the robustness of quantitative and qualitative food-web descriptors. Journal of Theoretical Biology 226:23-32.

Berlow, E. L., A.-M. Neutel, J. E. Cohen, P. C. De Ruiter, B. Ebenman, M. Emmerson, J. W. Fox, et al. 2004. Interaction strengths in food webs: issues and opportunities. Journal of Animal Ecology 73:585598.

Boecklen, W. J., C. T. Yarnes, B. A. Cook, and A. C. James. 2011. On the use of stable isotopes in trophic ecology. Annual Review of Ecology, Evolution, and Systematics 42:411-440.

Bolker, B. M., M. E. Brooks, C. J. Clark, S. W. Geange, J. R. Poulsen, M. H. H. Stevens, and J.-S. S. White. 2009. Generalized linear mixed models: a practical guide for ecology and evolution. Trends in Ecology and Evolution 24:127-135.

Bond, A. L., and A. W. Diamond. 2011. Recent Bayesian stableisotope mixing models are highly sensitive to variation in discrimination factors. Ecological Applications 21:1017-1023.

Carpenter, B., A. Gelman, M. D. Hoffman, D. Lee, B. Goodrich, M. Betancourt, M. Brubaker, J. Guo, P. Li, and A. Riddell. 2017. Stan: a probabilistic programming language. Journal of Statistical Software 76, https://doi.org/10.18637/jss.v076.i01.

Carpenter, S. R., J. J. Cole, M. L. Pace, M. Van de Bogert, D. L. Bade, D. Bastviken, C. M. Gille, J. R. Hodgson, J. F. Kitchell, and E. S. Kritzberg. 2005. Ecosystem subsidies: terrestrial support of aquatic food webs from ${ }^{13} \mathrm{C}$ addition to contrasting lakes. Ecology 86:27372750.

Cole, J. J., S. R. Carpenter, J. F. Kitchell, and M. L. Pace. 2002. Pathways of organic carbon utilization in small lakes: results from a whole-lake ${ }^{13} \mathrm{C}$ addition and coupled model. Limnology and Oceanography 47:1664-1675.

Collins, S. M., S. A. Thomas, T. Heatherly, K. L. MacNeill, A. O. H. C. Leduc, A. López-Sepulcre, B. A. Lamphere, et al. 2016. Fish introductions and light modulate food web fluxes in tropical streams: a whole-ecosystem experimental approach. Ecology 97:3154-3166.

Dodds, W. K., S. M. Collins, S. K. Hamilton, J. L. Tank, S. Johnson, J. R. Webster, K. S. Simon, et al. 2014. You are not always what we think you eat: selective assimilation across multiple wholestream isotopic tracer studies. Ecology 95:2757-2767.

Dodds, W. K., M. A. Evans-White, N. M. Gerlanc, L. Gray, D. A. Gudder, M. J. Kemp, A. L. López, et al. 2000. Quantification of the nitrogen cycle in a prairie stream. Ecosvstems 3:574-589.

Elton, C. S. 1927. Animal ecology. University of Chicago Press, Chicago, IL.

Elwood, J. W., and D. J. Nelson. 1972. Periphyton production and grazing rates in a stream measured with a ${ }^{32} \mathrm{P}$ material balance method. Oikos 23:295-303.
Gelman, A., J. Carlin, H. Stern, and D. Rubin. 2003. Bayesian data analysis. 2nd ed. Chapman \& Hall/CRC, Boca Raton, FL.

Geman, S., and D. Geman. 1984. Stochastic relaxation, Gibbs distributions, and the Bayesian restoration of images. IEEE Transactions on Pattern Analvsis and Machine Intelligence 6:721-741.

Goodale, C. L., G. Fredriksen, M. S. Weiss, C. K. McCalley, J. P. Sparks, and S. A. Thomas. 2015. Soil processes drive seasonal variation in retention of ${ }^{15} \mathrm{~N}$ tracers in a deciduous forest catchment. Ecology 96:2653-2668.

Green, P. J. 1995. Reversible jump Markov chain Monte Carlo computation and Bayesian model determination. Biometrika 82:711732.

Hooten, M. B., and N. T. Hobbs. 2015. A guide to Bayesian model selection for ecologists. Ecological Monographs 85:3-28.

Hutchinson, G. E., and V. T. Bowen. 1950. Limnological studies in Connecticut. IX. A quantitative radiochemical study of the phosphorus cycle in Linsley Pond. Ecology 31:194-203.

Iosifescu, M. 1980. Finite Markov processes and their applications. Wiley, Chichester.

Jardine, T. D., W. L. Hadwen, S. K. Hamilton, S. Hladyz, S. M. Mitrovic, K. A. Kidd, W. Y. Tsoi, et al. 2014. Understanding and overcoming baseline isotopic variability in running waters. River Research and Applications 30:155-165.

Jeschke, J. M., M. Kopp, and R. Tollrian. 2002. Predator functional responses: discriminating between handling and digesting prey. Ecological Monographs 72:95-112.

King, R. 2014. Statistical ecology. Annual Review of Statistics and Its Application 1:401-426.

Kling, G. W. 1994. Ecosystem-scale experiments. Pages 91-120 in Environmental chemistry of lakes and reservoirs. Advances in Chemistry. Vol. 237. American Chemical Society, Washington, DC.

Kohler, T. J., T. N. Heatherly, R. W. El-Sabaawi, E. Zandonà, M. C. Marshall, A. S. Flecker, C. M. Pringle, D. N. Reznick, and S. A. Thomas. 2012. Flow, nutrients, and light availability influence Neotropical epilithon biomass and stoichiometry. Freshwater Science 31:1019-1034.

Kulmatiski, A., K. H. Beard, R. J. T. Verweij, and E. C. February. 2010. A depth-controlled tracer technique measures vertical, horizontal and temporal patterns of water use by trees and grasses in a subtropical savanna. New Phytologist 188:199-209.

Ledger, M. E., L. E. Brown, F. K. Edwards, A. M. Milner, and G. Woodward. 2013. Drought alters the structure and functioning of complex food webs. Nature Climate Change 3:223-227.

Lima, M., N. C. Stenseth, and F. M. Jaksic. 2002. Food web structure and climate effects on the dynamics of small mammals and owls in semi-arid Chile. Ecology Letters 5:273-284.

Link, W. A., and R. J. Barker. 2010. Bayesian Inference: with ecological applications. Academic Press, London.

López-Sepulcre, A., M. Bruneaux, S. M. Collins, R. El-Sabaawi, A. S. Flecker, and S. A. Thomas. 2020. Data from: A new method to reconstruct quantitative food webs and nutrient flows from isotope tracer addition experiments. American Naturalist, Dryad Digital Repository, https://doi.org/10.5061/dryad.8sf7m0chx.

McCarthy, M. A., and P. Masters. 2005. Profiting from prior information in Bayesian analyses of ecological data. Iournal of Applied Ecology 42:1012-1019.

Middelburg, J. J., C. Barranguet, H. T. S. Boschker, P. M. J. Herman, T. Moens, and C. H. R. Heip. 2000. The fate of intertidal microphytobenthos carbon: an in situ ${ }^{13} \mathrm{C}$-labeling study. Limnology and Oceanography 45:1224-1234. 
Morris, I. 1974. Nitrogen assimilation and protein synthesis Pages 583-609 in W. D. P. Stewart, ed. Algal physiology and biochemistry. University of California Press, Berkeley.

Mulholland, P. J., J. L. Tank, D. M. Sanzone, W. M. Wollheim, B. J. Peterson, J. R. Webster, and J. L. Meyer. 2000. Nitrogen cycling in a forest stream determined by a ${ }^{15} \mathrm{~N}$ tracer addition. Ecological Monographs 70:471-493.

Mulholland, P. J., A. M. Helton, G. C. Poole, R. O. Hall, S. K. Hamilton, B. J. Peterson, J. L. Tank, et al. 2008. Stream denitrification across biomes and its response to anthropogenic nitrate loading. Nature 452:202-205.

Mulholland, R. J., and M. S. Keener. 1974. Analysis of linear compartment models for ecosystems. Journal of Theoretical Biology 44:105-116.

Newbold, J. D., J. W. Elwood, R. V. O’Neill, and A. L. Sheldon. 1983. Phosphorus dynamics in a woodland stream ecosystem: a study of nutrient spiralling. Ecology 64:1249-1265.

Norman, B. C., M. R. Whiles, S. M. Collins, A. S. Flecker, S. K. Hamilton, S. L. Johnson, E. J. Rosi, et al. 2017. Drivers of nitrogen transfer in stream food webs across continents. Ecology 98:30443055.

O'Brien, W. J. 1974. The dynamics of nutrient limitation of phytoplankton algae: a model reconsidered. Ecology 55:135-141

Pace, M. L., J. J. Cole, S. R. Carpenter, J. F. Kitchell, J. R. Hodgson, M. C. Van de Bogert, D. L. Bade, E. S. Kritzberg, and D. Bastviken. 2004. Whole-lake carbon-13 additions reveal terrestrial support of aquatic food webs. Nature 427:240-243.

Paine, R. T. 1980. Food webs: linkage, interaction strength and community infrastructure. Iournal of Animal Ecology 49:667-685.

Patten, B. C., and M. Witkamp. 1967. Systems analysis of ${ }^{134}$ cesium kinetics in terrestrial microcosms. Ecology 48:813-824.

Peterson, B. J., and B. Fry. 1987. Stable isotopes in ecosystem studies. Annual Review of Ecology and Systematics 18:293-320.

Peterson, B. J., W. M. Wollheim, P. J. Mulholland, J. R. Webster, J. L. Meyer, J. L. Tank, E. Martí, et al. 2001. Control of nitrogen export from watersheds by headwater streams. Science 292:86-90.

Post, D. M. 2002. Using stable isotopes to estimate trophic position: models, methods, and assumptions. Ecology 83:703-718.

R Core Team. 2019. R: a language and environment for statistical computing. R Foundation for Statistical Computing, Vienna.

Rigler, F. H. 1956. A tracer study of the phosphorus cycle in lake water. Ecology 37:550-562.

Rooney, N., and K. S. McCann. 2012. Integrating food web diversity, structure and stability. Trends in Ecology and Evolution 27:40-46.

Roslin, T., and S. Majaneva. 2016. The use of DNA barcodes in food web construction - terrestrial and aquatic ecologists unite! Genome 59:603-628.

Spiegelhalter, D. J., N. G. Best, B. P. Carlin, and A. Van Der Linde. 2002. Bayesian measures of model complexity and fit. Lournal of the Roval Statistical Society B 64:583-639.

Stan Development Team. 2019. RStan: the R interface to Stan. R package version 2.19.2.

Tank, J. L., E. Martí, T. Riis, D. von Schiller, A. J. Reisinger, W. K. Dodds, M. R. Whiles, et al. 2018. Partitioning assimilatory nitrogen uptake in streams: an analysis of stable isotope tracer additions across continents. Ecological Monographs 88:120-138.

Tenan, S., R. B. O'Hara, I. Hendriks, and G. Tavecchia. 2014. Bayesian model selection: the steepest mountain to climb. Ecological Modelling 283:62-69.
Travis, J., D. Reznick, R. D. Bassar, A. López-Sepulcre, R. H. J. Ferriere, and T. Coulson. 2014. Do eco-evo feedbacks help us understand nature? answers from studies of the Trinidadian guppy. Advances in Ecological Research 50:1-40.

Vannote, R. L., G. W. Minshall, K. W. Cummins, J. R. Sedell, and C. E. Cushing. 1980. The river continuum concept. Canadian Journal of Fisheries and Aquatic Sciences 37:130-137.

Whiles, M. R., R. O. Hall, W. K. Dodds, P. Verburg, A. D. Huryn, C. M. Pringle, K. R. Lips, et al. 2013. Disease-driven amphibian declines alter ecosystem processes in a tropical stream. Ecosystems 16:146-157.

Whittaker, R. H. 1961. Experiments with radiophosphorus tracer in aquarium microcosms. Ecological monographs 31:157-188.

Zucchini, W., and I. L. MacDonald. 2009. Hidden Markov models for time series: an introduction using R. Chapman \& Hall/CRC, Boca Raton, FL.

\section{References Cited Only in the Online Enhancements}

Baumgartner, D., and K.-O. Rothhaupt. 2003. Predictive length-dry mass regressions for freshwater invertebrates in a pre-alpine lake littoral. International Review of Hydrobiology 88:453-463.

Benke, A. C., A. D. Huryn, L. A. Smock, and J. B. Wallace. 1999. Length-mass relationships for freshwater macroinvertebrates in North America with particular reference to the southeastern United States. Journal of the North American Benthological Society 18:308-343.

Holmes, R. M., J. W. McClelland, D. M. Sigman, B. Fry, and B. J. Peterson. 1998. Measuring ${ }^{15} \mathrm{~N}_{-}-\mathrm{NH}_{4}{ }^{+}$in marine, estuarine and fresh waters: an adaptation of the ammonia diffusion method for samples with low ammonium concentrations. Marine Chemistry 60:235-243.

Loeb, S. L. 1981. An in situ method for measuring the primary productivity and standing crop of the epilithic periphyton community in lentic systems. Limnology and Oceanography 26:394-399.

Miyasaka, H., H.-K. Motomi, Y. Miyake, D. Kishi, I. Katano, H. Doi, S. Ohba, and N. Kuhara. 2008. Relationships between length and weight of freshwater macroinvertebrates in Japan. Limnology 9:75-80.

Murphy, J., and J. P. Riley. 1962. A modified single solution method for the determination of phosphate in natural waters. Analytica Chimica Acta 27:31-36.

Sabo, J. L., J. L. Bastow, and M. A. Powers. 2002. Length-mass relationships for adult aquatic and terrestrial invertebrates in a California watershed. Journal of the North American Benthological Society 21:336-343.

Sigman, D. M., M. A. Altabet, R. Michener, D. C. McCorkle, B. Fry, and R. M. Holmes. 1997. Natural abundance-level measurement of the nitrogen isotopic composition of oceanic nitrate: an adaptation of the ammonia diffusion method. Marine Chemistry 57:227242.

Taylor, B. W., C. F. Keep, R. O. Hall, B. J. Koch, L. S. Tronstad, A. S. Flecker, and A. J. Ulseth. 2007. Improving the fluorometric ammonium method: matrix effects, background fluorescence, and standard additions. Journal of the North American Benthological Society 26:167-177. 


\title{
Appendix from A. López-Sepulcre et al., "A New Method to Reconstruct Quantitative Food Webs and Nutrient Flows from Isotope Tracer Addition Experiments" (Am. Nat., vol. 195, no. 6, p. 964)
}

\author{
Tracer Drip, Sampling, and Chemical Analysis \\ Biomass Sampling
}

Biomass of food web compartments and water chemistry in both streams were monitored in March 2010 before isotope tracer releases began and in May 2010 after sampling concluded. Each stream had three biomass sampling sites. We sampled one pool and one riffle at each of the six sampling sites for a total of six samples per stream. Total biomass was calculated assuming that $60 \%$ of the benthic area is composed by riffles.

We collected filtered water samples for soluble reactive phosphorus (SRP) and nitrate $\left(\mathrm{NO}_{3}{ }^{-}\right)$that were frozen and returned to the United States for analysis. Nitrate samples were analyzed using a Dionex ICS-90 ion chromatography system with Chromeleon software (Dionex), and SRP samples were analyzed on a Pharmacia LKB Ultraspec III spectrophotometer (model 80-2097-62; Pharmacia Biotech) using a method developed by Murphy and Riley (1962). We analyzed ammonium $\left(\mathrm{NH}_{4}{ }^{+}\right.$) water chemistry in the field using fluorometric methods with an Aquaflor handheld fluorometer (Turner Designs, Sunnyvale, CA). Ammonium samples were collected in brown opaque bottles and kept cold for up to $6 \mathrm{~h}$ until they were reacted with orthophthaldialdehyde (OPA). Fluorescence was measured 2-3 h after the OPA reagent was added. We created a standard curve with stream water samples to correct for matrix effects and converted fluorescence to $\mathrm{NH}_{4}^{+}$concentration (Taylor et al. 2007).

Because both streams contained many large rocks and bedrock that could not be removed from the stream and scrubbed, we sampled epilithon with modified Loeb samplers (Loeb 1981). Seven Loeb samples per sampling site were combined into a single sample for analysis. Epilithon samples were subsampled and filtered through glass fiber filters (Whatman GF/F; 0.7- $\mu \mathrm{m}$ pore size) to analyze chlorophyll $a$ and ash-free dry mass (AFDM). Suspended organic matter (seston) was collected on Whatman GF/F filters in the field by filtering a known quantity of stream water, between 1 and $2 \mathrm{~L}$ depending on seston concentration. Fine benthic organic matter (FBOM) was sampled by sinking a plastic cylinder (bottom area, $530 \mathrm{~cm}^{2}$ ) into an area of soft sediment, measuring the water depth in the cylinder, mixing the surface layer of organic matter into the water, and removing a known quantity of slurry from the cylinder. Coarse benthic organic matter (CBOM) was sampled by haphazardly selecting a location on the stream and removing all leaf litter and woody material in a $0.5-\mathrm{m}$-wide transect that stretched across the width of the stream at the selected location. We dried epilithon AFDM, seston, FBOM, and $\mathrm{CBOM}$ samples at $50^{\circ} \mathrm{C}$ until they reached a constant mass and recorded all biomasses. After recording the mass of epilithon AFDM filters, we ashed filters at $450^{\circ} \mathrm{C}$ for $6 \mathrm{~h}$ and recorded the mass of the filter plus ash.

Invertebrates were sampled at the same transects as basal resource compartments using a Hess sampler with a 0.032- $\mathrm{m}^{2}$ area and a $250-\mu \mathrm{m}$ net. We preserved invertebrate samples in $90 \%$ ethanol and returned them to the United States for processing and enumeration. Biomass was calculated using standard length-mass relationships (Benke et al. 1999; Sabo et al. 2002; Baumgartner and Rothhaupt 2003; Miyasaka et al. 2008; T. Heatherly, unpublished data).

\section{${ }^{15} \mathrm{~N}$-Ammonium Addition}

We added ${ }^{15} \mathrm{~N}$-labeled ammonium (as dissolved ${ }^{15} \mathrm{NH}_{4} \mathrm{Cl}$ ) to both study reaches: canopy thinned (Upper La Laja) and natural canopy (Lower La Laja). We added the isotope using a continuous drip with an injection rate of $10 \mathrm{~mL} \mathrm{~min}^{-1}$ over a 10-day period from March 7 to 16, 2010. The injections increased the $\delta^{15} \mathrm{~N}$ of dissolved ammonium to approximately 20,000. The target enrichment was not intended to fertilize the system, and the concentration of ${ }^{15} \mathrm{~N}$ added was $<5 \%$ of ambient $\mathrm{NH}_{4}{ }^{+}$. We also added rhodamine fluorescent dye as a conservative tracer throughout the course of the isotope release, which we used to correct for dilution along the study reach. 


\section{Isotope Sampling and Analysis}

We sampled food web compartments to track the fate of the isotope tracers at three stations downstream of each point of isotope release $(\sim 15,30$, and 60 m downstream, depending on the reach). Samples were collected on 3 days during the 10-day isotope release (days 3, 7, and 10) and on 5 days during the month following the isotope release (days 13, 17, 20, 30, and 40). Sampled food web compartments included water chemistry $\left({ }^{15} \mathrm{NO}_{3}{ }^{-}\right.$and ${ }^{15} \mathrm{NH}_{4}{ }^{+}$), epilithon, FBOM (sampled from the sediment surface via suction), CBOM, seston, and eight common invertebrate taxa representing all functional feeding groups (predators, grazers, collector-gatherers, collector-filterers, and shredders). Invertebrate taxa selected were sufficiently large bodied and abundant that they could be collected by hand with minimal disturbance to the streambed. Many of the invertebrate taxa we collected (Eudaniela, Euthyplocia, Psephenus, Leptonema, Tricorythodes, and Argia) are among the dominant taxa in both streams, but two of our sampled invertebrate groups, Petrophila sp. and Phylloicus sp., were not among the most abundant invertebrate taxa but represented functional feeding groups (scraper and shredder, respectively) distinct from those dominant in the streams. We were unable to collect some small-bodied but abundant taxa (e.g., chironomids) because we could not collect enough individuals for isotope sample analysis without causing a major disturbance to the streambed. We also collected background samples from each compartment to correct for background isotopic values. Background samples were collected either prior to the start of the experiment or from upstream of the control reach tracer addition point.

We dried all samples at $50^{\circ} \mathrm{C}$ and conducted isotopic analyses at the University of Georgia isotope analysis facility. Basal resource sampling protocols were the same as the biomass sampling techniques, but for invertebrates we handpicked individuals by turning over rocks and sorting through organic matter in plastic trays to minimize disturbance and ensure that sufficient numbers of each taxon were collected for isotopic analysis. We also measured water column ${ }^{15} \mathrm{~N}$, which we measured with a filter pack diffusion technique (Sigman et al. 1997; Holmes et al. 1998). Specifically, we collected $900 \mathrm{~mL}$ of water in 1-L plastic cubitainers for ${ }^{15} \mathrm{NH}_{4}{ }^{+}$samples and added a $60-\mu \mathrm{g}$ spike of $\mathrm{N}_{\text {as }} \mathrm{NH}_{4}{ }^{+}$ to increase $\mathrm{N}$ mass to a level that is detectable by a mass spectrometer. We collected $500 \mathrm{~mL}$ of water for ${ }^{15} \mathrm{NO}_{3}{ }^{-} \mathrm{samples}$ and transferred samples in $250-\mathrm{mL}$ Nalgene bottles after boiling to reduce volume to $\sim 100 \mathrm{~mL}$. Ammonium from all samples was allowed to diffuse onto a 1.0-cm Whatman GF/D (2.7- $\mu \mathrm{m}$ pore size) filter sealed in Teflon tape for at least 3 weeks before filters were harvested and dried at $50^{\circ} \mathrm{C}$. 


\section{A new method to reconstruct quantitative food webs and nutrient flows from isotope tracer addition experiments.}

Andrés López-Sepulcre ${ }^{1,2,3^{*}}$, Matthieu Bruneaux ${ }^{2}$, Sarah M. Collins ${ }^{4}$, Rana El-Sabaawi ${ }^{5}$, Alexander S Flecker ${ }^{6}$, and Steven A. Thomas ${ }^{7}$

${ }^{1}$ Department of Biology, Washington University in St. Louis, MO, USA ${ }^{2}$ Department of Biological and Environmental Sciences, University of Jyväskylä, Finland

${ }^{3}$ CNRS UMR 7618, Institute of Ecology and Environmental Sciences of Paris (iEES), Sorbonne Université, France

${ }^{4}$ Department of Zoology and Physiology, University of Wyoming, USA ${ }^{5}$ Department of Biology, University of Victoria, Canada

${ }^{6}$ Department of Ecology and Evolutionary Biology, Cornell University, USA

${ }^{7}$ School of Natural Resources, University of Nebraska-Lincoln, USA

${ }^{*}$ Corresponding author. E-mail: alopezsepulcre@wustl.edu

January 15, 2020 


\section{Supplementary Material S1. Implementation of the model for MCMC sampling}

We sampled the posterior distributions of the model parameters using the Stan program and its R interface RStan (Carpenter et al., 2017; Stan Development Team, 2019). Stan implements Hamiltonian Monte Carlo (HMC) sampling, which allows for more efficient and reliable sampling of complex model posterior than a simple Metropolis-Hastings algorithm, especially as the dimension of the posterior increases.

Here, we present the model implementation in Stan by describing the data passed to the sampler, the priors used and the likelihood calculation. Our description is valid for either stream (UL and LL): we ran the model independently for both stream, and then combined the DIC values obtained for a given foodweb topology.

The model is based on solving numerically the system of differential equations describing the foodweb topology to calculate the trajectories of marked and unmarked nutrients based on a set of parameter values. The numerical solving of the differential equations is done using a simple discretization approach with a reasonably small $d t$ value, and projecting the trajectories iteratively.

\section{Data passed to Stan}

The data passed to Stan for one stream comprises (using the notations from Table 1):

- a matrix of the same size as $\boldsymbol{\Psi}_{\mathbf{h}}$ containing 0 and 1 values, and serving as a mask defining the directed connections existing between the foodweb compartments,

- the $d t$ value of the time step used for the numerical solving of the system of differential equations describing the foodweb,

- for each transect, a vector describing the initial isotopic proportions $\mathbf{z}^{(s, 0)}$ (i.e. the initial isotopic proportions for each compartment),

- for each transect, a table providing the observed data $z_{\text {obs }, i}^{(s, t)}$ as one observation of proportion of marked tracer per row (with columns being the compartment observed and the time of observation),

- for each transect and for each inorganic nutrient compartment $i \in \mathcal{I}$, one table giving the pre-computed $n_{i}^{(t)}$ and $m_{i}^{(t)}$ values for every time step that will be used when solving the ODE system (those tables are calculated from the step functions based on the measured isotopic profiles for $\mathrm{NH}_{4}^{+}$and $\mathrm{NO}_{3}^{-}$),

- shared across all transects of the stream, the initial biomass of each compartment (calculated from $x_{\mathrm{obs}, i}^{(s, t)}$ ) and its estimated standard deviation $\mathrm{SD}_{i}$.

\section{Sampled parameters and their priors}

The parameters sampled by Stan are:

- all the non-zero uptake rates $v_{i, j}$ from compartment $j$ to compartment $i$, 
- all the non-zero loss rates $\lambda_{j}$ from compartment $j$ (i.e. for all organic compartments),

- the active portions $\pi_{i}$ for the primary producers (CBOM, FBOM, epilithon, seston),

- the coefficient of variation $\eta$ for observed isotopic ratios

The priors we used were:

$$
\begin{aligned}
v_{i, j} & \sim \operatorname{Half} \text {-Cauchy }(\text { scale }=250) \text { for input compartments } j \in \mathcal{I} \\
v_{i, j} & \sim \operatorname{Beta}(\alpha=1, \beta=3, \text { scale }=1) \text { for all other uptake rates } v_{i, j}>0 \\
\lambda_{i} & \sim \operatorname{Beta}(\alpha=1, \beta=3, \text { scale }=1) \\
\pi_{i} & \sim \operatorname{Uniform}(0,1) \text { for all basal compartments } \pi_{i}<1 \\
\eta & \sim \operatorname{Half-Cauchy}(\text { scale }=1)
\end{aligned}
$$

with the following compartment-specific adjustments:

$$
\begin{aligned}
v_{\text {eudan }, \text { CBOM }} & \sim \operatorname{Beta}(\alpha=1, \beta=3, \text { scale }=0.5) \\
v_{\text {lepto,seston }} & \sim \operatorname{Beta}(\alpha=1, \beta=3, \text { scale }=0.5)
\end{aligned}
$$

where we defines $X$ as following a scaled beta distribution $\operatorname{Beta}(\alpha, \beta$, scale $)$ if $\frac{X}{\text { scale }}$ follows a beta distribution $\operatorname{Beta}(\alpha, \beta)$.

\section{Likelihood calculation}

Below is a pseudo-code for the calculation of the likelihood of a set of parameter values. It is applied for each transect of a stream.

1. Build the matrix $\Psi$ using the parameter values to evaluate. The refractory portions $1-\pi_{i}$ are included as separate, static compartments with no connection to any other compartment and no loss in an expanded $\boldsymbol{\Psi}$, i.e. only 0s on the corresponding rows and columns in the expanded $\boldsymbol{\Psi}$.

2. Build initial values of $\mathbf{n}^{(0)}$ and $\mathbf{m}^{(0)}$ using the mean of observed biomasses for compartments $\left\{\bar{x}_{\mathrm{obs}, 1}, \bar{x}_{\mathrm{obs}, 2}, \ldots, \bar{x}_{\mathrm{obs}, C}\right\}$, initial $\delta^{15} \mathrm{~N}$ values, and parameter values $\pi$ (active portions of compartments).

3. Set $t=0$. While $t \leq 40$ (40 days is the latest timepoint with observations):

(a) $\mathbf{n}^{(t+d t)}=\boldsymbol{\Psi} \cdot \mathbf{n}^{(t)}$ and $\mathbf{m}^{(t+d t)}=\boldsymbol{\Psi} \cdot \mathbf{m}^{(t)}$ (Equation 1)

(b) Set $t \leftarrow t+d t$

(c) Update $n_{i}^{(t)}$ and $m_{i}^{(t)}$ for inorganic nutrient sources $i \in \mathcal{I}$ based on the pre-computed tables giving their values for each time point

4. Calculate the trajectories for biomasses $\mathbf{x}^{(t)}$ and proportions of marked tracer $\mathbf{z}^{(t)}$

(a) $\mathbf{x}^{(t)}=\mathbf{m}^{(t)}+\mathbf{x}^{(t)}$ 
(b) $\mathbf{z}^{(t)}=\mathbf{m}^{(t)} \oslash \mathbf{x}^{(t)}$ (Equation 10)

5. Update $\mathbf{x}^{(t)}$ and $\mathbf{z}^{(t)}$ by merging active and refractory portions of split compartments into single observed compartments, using weighed averages according to $\pi$.

6. For each non-source compartment $i \notin \mathcal{I}$ :

(a) Set $t_{i}$ the timepoints for which this compartment was sampled

(b) Extract values $z_{i}^{t_{i}}$ calculated in 4.b.

(c) Update likelihood assuming $z_{\mathrm{obs}, i}^{t_{i}} \sim$ Gamma $^{*}\left(z_{i}^{(t)}, \eta\right)$ (Equation 12)

(d) Extract values $x_{i}^{t_{i}}$ calculated in 4.a.

(e) Update likelihood assuming $x_{\mathrm{obs}, i}^{t_{i}} \sim \operatorname{TN}$ Norm lower $=0\left(x_{i}^{\left(t_{0}\right)}, \mathrm{SD}_{i}\right)$, where $x_{i}^{\left(t_{0}\right)}$ is the initial biomass of this compartment (i.e. the mean of observed biomasses for this compartment, potentially adjusted if the compartment is an active or refractory portion of an observed compartment), and $\mathrm{SD}_{i}$ is the standard deviation of observed biomasses for this compartment. 


\section{Supplementary Material S2. Supplementary tables and figures}

\begin{tabular}{|c|c|c|}
\hline Parameter & LL estimate & UL estimate \\
\hline$\pi_{\text {epi }}$ & $0.136[0.0114-0.274]$ & $0.45[0.238-0.727]$ \\
\hline$\pi_{\mathrm{CBOM}}$ & $0.19[0.0187-0.439]$ & $0.394[0.0929-0.651]$ \\
\hline$\pi_{\mathrm{FBOM}}$ & $0.0775[0.028-0.151]$ & $0.0503[0.0046-0.108]$ \\
\hline$\pi_{\mathrm{ses}}$ & $0.134[0.0151-0.292]$ & $0.35[0.238-0.475]$ \\
\hline$v_{\text {epi,NH4 }}$ & $31.8[20.7-48.4]$ & $50.1[36.5-68.7]$ \\
\hline$v_{\mathrm{CBOM}, \mathrm{NH} 4}$ & $14.4[3.62-58.1]$ & $41.3[22.5-84.6]$ \\
\hline$v_{\mathrm{FBOM}, \mathrm{NH} 4}$ & $85.6[44.8-138]$ & $134[75.4-216]$ \\
\hline$v_{\mathrm{ses}, \mathrm{NH} 4}$ & $0.0288[0.0185-0.0503]$ & $0.0146[0.0113-0.019]$ \\
\hline$v_{\text {epi,NO3 }}$ & $0.00805[0.000328-0.0409]$ & $0.404[0.0698-0.847]$ \\
\hline$v_{\mathrm{CBOM}, \mathrm{NO} 3}$ & $0.401[0.0477-1.94]$ & $1.08[0.269-2.72]$ \\
\hline$v_{\mathrm{FBOM}, \mathrm{NO} 3}$ & $0.271[0.0186-0.852]$ & $0.248[0.0121-0.79]$ \\
\hline$v_{\mathrm{ses}, \mathrm{NO} 3}$ & $0.000122[0.00000865-0.000366]$ & $0.0000311[0.00000323-0.0000849]$ \\
\hline$v_{\text {pet,epi }}$ & $0.0000587[0.0000397-0.0000855]$ & $0.000224[0.0000902-0.000528]$ \\
\hline$v_{\text {pse,epi }}$ & $0.00443[0.00325-0.00629]$ & $0.00344[0.00232-0.00504]$ \\
\hline$v_{\text {eud,CBOM }}$ & $0.0173[0.00357-0.102]$ & $0.00594[0.00197-0.0182]$ \\
\hline$v_{\text {phy }, \mathrm{CBOM}}$ & $0.000449[0.00011-0.00281]$ & $0.0000896[0.0000253-0.000363]$ \\
\hline$v_{\text {tri,FBOM }}$ & $0.00197[0.000667-0.00519]$ & $0.0037[0.00169-0.00888]$ \\
\hline$v_{\text {lep,ses }}$ & $0.0555[0.0341-0.0911]$ & $0.0449[0.0119-0.0801]$ \\
\hline$v_{\text {arg,pet }}$ & $0.0122[0.000531-0.0447]$ & $0.0632[0.012-0.142]$ \\
\hline$v_{\text {arg,tri }}$ & $0.0216[0.005-0.0773]$ & $0.0183[0.00553-0.0591]$ \\
\hline$v_{\text {eut,tri }}$ & $0.119[0.0217-0.38]$ & $0.0817[0.0194-0.236]$ \\
\hline$\lambda_{\text {epi }}$ & $0.217[0.131-0.343]$ & $0.189[0.126-0.264]$ \\
\hline$\lambda_{\mathrm{CBOM}}$ & $0.282[0.0274-0.773]$ & $0.165[0.0668-0.382]$ \\
\hline$\lambda_{\mathrm{FBOM}}$ & $0.059[0.0295-0.0894]$ & $0.0882[0.0528-0.17]$ \\
\hline$\lambda_{\text {ses }}$ & $0.0708[0.00454-0.224]$ & $0.0168[0.000626-0.0531]$ \\
\hline$\lambda_{\text {pet }}$ & $0.013[0.000584-0.0455]$ & $0.0244[0.000928-0.101]$ \\
\hline$\lambda_{\text {pse }}$ & $0.0268[0.0135-0.0445]$ & $0.0296[0.00931-0.056]$ \\
\hline$\lambda_{\text {tri }}$ & $0.393[0.085-0.775]$ & $0.124[0.017-0.334]$ \\
\hline$\lambda_{\text {lep }}$ & $0.0306[0.0046-0.085]$ & $0.543[0.396-0.835]$ \\
\hline$\lambda_{\text {eud }}$ & $0.0336[0.00216-0.13]$ & $0.0416[0.00781-0.133]$ \\
\hline$\lambda_{\text {phy }}$ & $0.103[0.0314-0.705]$ & $0.167[0.0649-0.584]$ \\
\hline$\lambda_{\arg }$ & $0.0612[0.0184-0.166]$ & $0.13[0.0762-0.228]$ \\
\hline$\lambda_{\text {eut }}$ & $0.0224[0.00104-0.111]$ & $0.0209[0.000918-0.119]$ \\
\hline$\eta$ & $0.096[0.0878-0.105]$ & $0.104[0.0945-0.115]$ \\
\hline
\end{tabular}

Supplementary Table 1: Estimates of primary parameters (median and 95\% credible interval) from the best model, $\boldsymbol{\Psi}_{100}$, for the closed closed canopy (LL) and open canopy (UL) streams. 


\begin{tabular}{lcc}
\hline \multirow{2}{*}{ Compartment $i$} & \multicolumn{2}{c}{ Biomass $\hat{X}_{i}\left(\mathrm{mgN} / \mathrm{m}^{2}\right)$} \\
\cline { 2 - 3 } & $\mathrm{LL}$ & $\mathrm{UL}$ \\
\hline Epilithon & $226[192-258]$ & $329[279-382]$ \\
active & $44.5[34.7-57.4]$ & $146[83.8-246]$ \\
refractory & $181[152-207]$ & $181[89.9-251]$ \\
CBOM & $879[623-1100]$ & $948[528-1490]$ \\
active & $72[9.21-276]$ & $266[91.9-664]$ \\
refractory & $793[549-960]$ & $660[380-987]$ \\
FBOM & $5410[4990-6300]$ & $5500[5190-6100]$ \\
active & $584[259-1350]$ & $518[259-966]$ \\
refractory & $4860[4470-5120]$ & $5000[4700-5240]$ \\
Seston & $0.663[0.552-0.771]$ & $0.244[0.228-0.263]$ \\
active & $0.0983[0.0536-0.192]$ & $0.0856[0.061-0.12]$ \\
refractory & $0.56[0.457-0.637]$ & $0.158[0.128-0.186]$ \\
Petrophila & $0.0908[0.0333-0.418]$ & $0.362[0.0648-1.62]$ \\
Psephenus & $7.54[4.44-14.2]$ & $18[8.73-41.5]$ \\
Tricorythodes & $2.2[0.681-4.71]$ & $8.58[3.1-16]$ \\
Leptonema & $0.19[0.0548-0.995]$ & $0.00692[0.00161-0.015]$ \\
Eudaniela & $41.2[3.82-484]$ & $41.5[8.71-155]$ \\
Phylloicus & $0.276[0.0634-0.676]$ & $0.148[0.0281-0.37]$ \\
Argia & $0.871[0.0857-4.27]$ & $1.45[0.345-3.55]$ \\
Euthyplocia & $11.9[0.511-402]$ & $35.9[1.3-911]$ \\
\hline
\end{tabular}

Supplementary Table 2: Steady state compartment biomasses in $\mathrm{mgN} / \mathrm{m}^{2}$ estimated as the sum of the first two right eigenvectors of $\boldsymbol{\Psi}_{100}$. 


\begin{tabular}{|c|c|c|c|c|}
\hline \multirow{2}{*}{ Compartment $i$} & \multicolumn{2}{|c|}{ Uptake $F_{i, .}\left(\mathrm{mgN} \mathrm{m}^{-2}\right.$ day $\left.^{-1}\right)$} & \multicolumn{2}{|c|}{ Turnover time $T_{i}^{\prime}$ (days) } \\
\hline & LL & UL & LL & $\mathrm{UL}$ \\
\hline \multirow[t]{3}{*}{ Epilithon } & 9.88 & 27.6 & 33.5 & 11.8 \\
\hline & {$[6.42-15]$} & {$[17.6-42.9]$} & {$[13.5-436]$} & {$[7.56-20.9]$} \\
\hline & 6.52 & 24.9 & 35.71 & 15.38 \\
\hline \multirow[t]{3}{*}{ CBOM } & 17.3 & 46.4 & 23.4 & 15.8 \\
\hline & {$[3.05-75.9]$} & [16.9-108] & {$[4.5-229]$} & {$[5.71-66.6]$} \\
\hline & 6.52 & 24.9 & 35.71 & 15.38 \\
\hline \multirow[t]{3}{*}{ FBOM } & 35.2 & 49.3 & 213 & 222 \\
\hline & {$[17.5-62.3]$} & {$[27-81.6]$} & {$[83.8-851]$} & [84.5-2390] \\
\hline & 128 & 244 & 29.41 & 36.71 \\
\hline \multirow[t]{3}{*}{ Seston } & 0.0127 & 0.00541 & 61.8 & 45.2 \\
\hline & {$[0.00717-0.0233]$} & [0.00386-0.00773] & {$[22.1-533]$} & {$[32-66.4]$} \\
\hline & 0.55 & 0.222 & 21.28 & 16.13 \\
\hline \multirow[t]{3}{*}{ Petrophila } & 0.0026 & 0.0319 & 34 & 10.5 \\
\hline & [0.0019-0.00366] & [0.01-0.113] & {$[15.7-145]$} & {$[5.73-25.1]$} \\
\hline & 0.012 & 0.111 & 12.6 & 11.6 \\
\hline \multirow[t]{3}{*}{ Psephenus } & 0.196 & 0.505 & 37.3 & 33.7 \\
\hline & [0.154-0.269] & [0.264-0.952] & {$[22.5-74.2]$} & [17.8-107] \\
\hline & 0.263 & 0.459 & 19.7 & 30 \\
\hline \multirow[t]{3}{*}{ Tricorythodes } & 1.16 & 1.92 & 1.81 & 4.25 \\
\hline & {$[0.412-2.79]$} & [0.943-4.01] & [1.03-3.76] & {$[2.14-8.32]$} \\
\hline & 0.392 & 2.83 & 6.26 & 3.78 \\
\hline \multirow[t]{3}{*}{ Leptonema } & 0.00549 & 0.00391 & 32.7 & 1.84 \\
\hline & [0.0027-0.0112] & [0.00106-0.00664] & {$[11.8-217]$} & {$[1.2-2.52]$} \\
\hline & 0.01 & 0.296 & 23.7 & 10.9 \\
\hline \multirow[t]{3}{*}{ Eudaniela } & 1.17 & 1.54 & 29.8 & 24 \\
\hline & {$[0.273-5.04]$} & {$[0.513-5.45]$} & {$[7.72-464]$} & [7.51-128] \\
\hline & 4.3 & 2.7 & 173 & 149 \\
\hline \multirow[t]{3}{*}{ Phylloicus } & 0.0273 & 0.0241 & 9.75 & 6 \\
\hline & [0.00726-0.22] & [0.00571-0.0968] & [1.42-31.8] & [1.71-15.4] \\
\hline & 0.11 & 0.108 & 7.8 & 27.3 \\
\hline \multirow[t]{3}{*}{ Argia } & 0.049 & 0.181 & 16.3 & 7.7 \\
\hline & [0.0131-0.124] & {$[0.0688-0.367]$} & [6.03-54.3] & [4.39-13.1] \\
\hline & 0.02 & 0.02 & 25.7 & 13.6 \\
\hline \multirow[t]{3}{*}{ Euthyplocia } & 0.254 & 0.709 & 44.6 & 47.9 \\
\hline & [0.0516-0.676] & {$[0.159-1.41]$} & [8.98-962] & [8.42-1090] \\
\hline & 0.3 & 0.8 & 104.2 & 93.6 \\
\hline
\end{tabular}

Supplementary Table 3: Flux and turnover time estimates and 95\% credible intervals. Estimates from Collins et al. (2016) are shown in italics for comparison. 

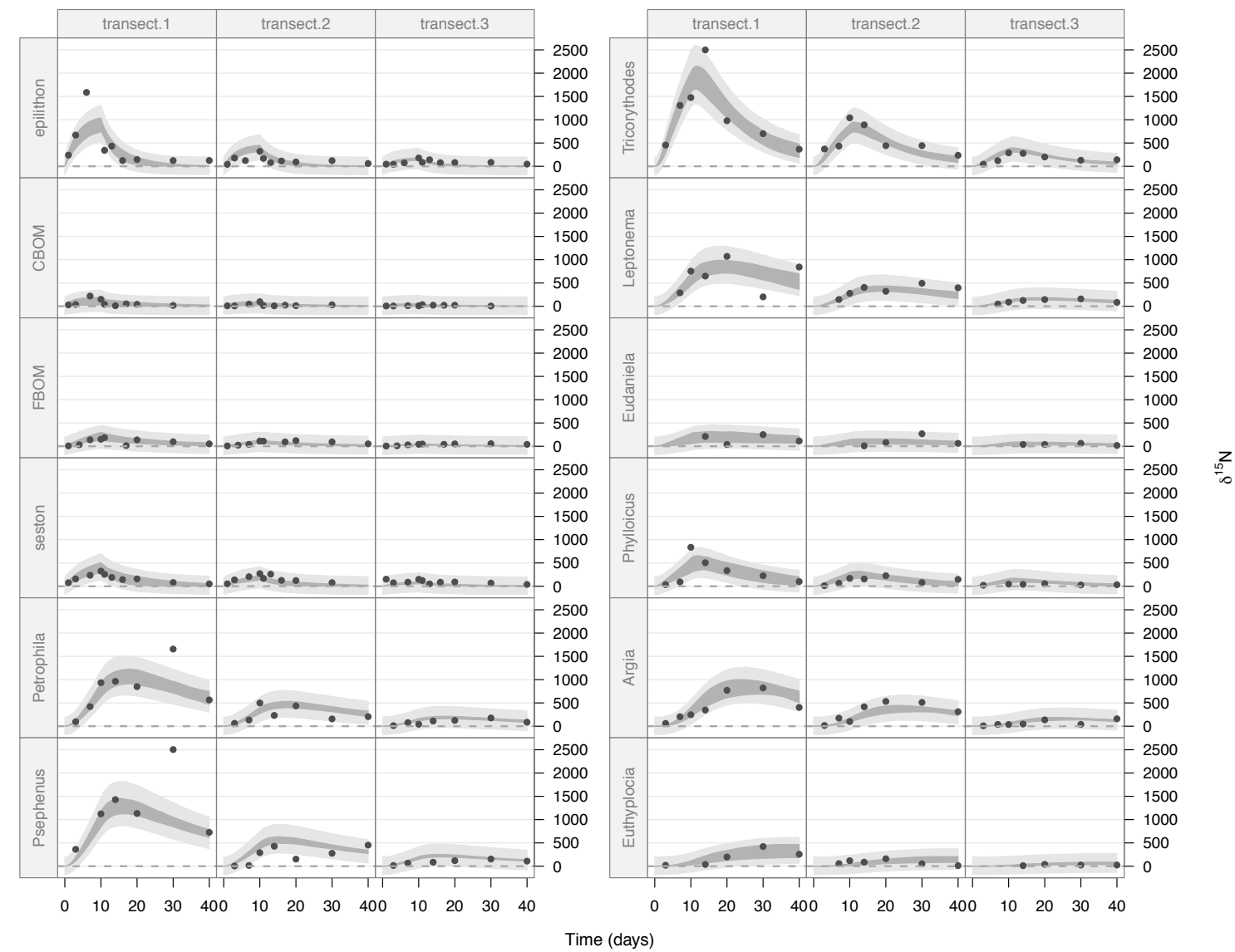

(a) Lower La Laja (LL) 


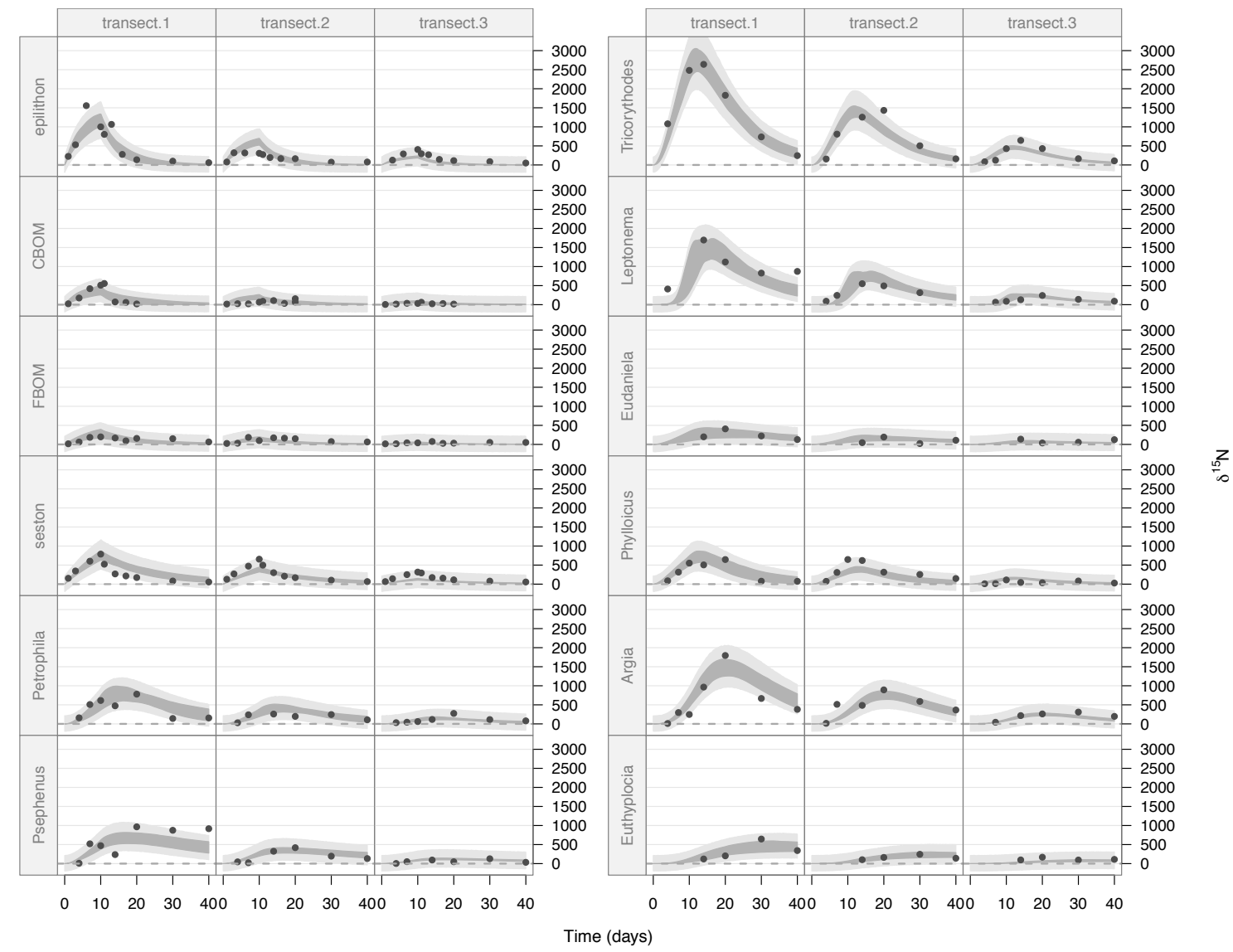

(b) Upper La Laja (UL)

Supplementary Figure 1: Model fit for comparing data with credible and prediction envelopes $\left(\delta^{15} \mathrm{~N}\right)$. Solid dots are observed data; dark grey envelopes are $95 \%$ credible intervals; and light grey envelopes are $95 \%$ prediction intervals. 


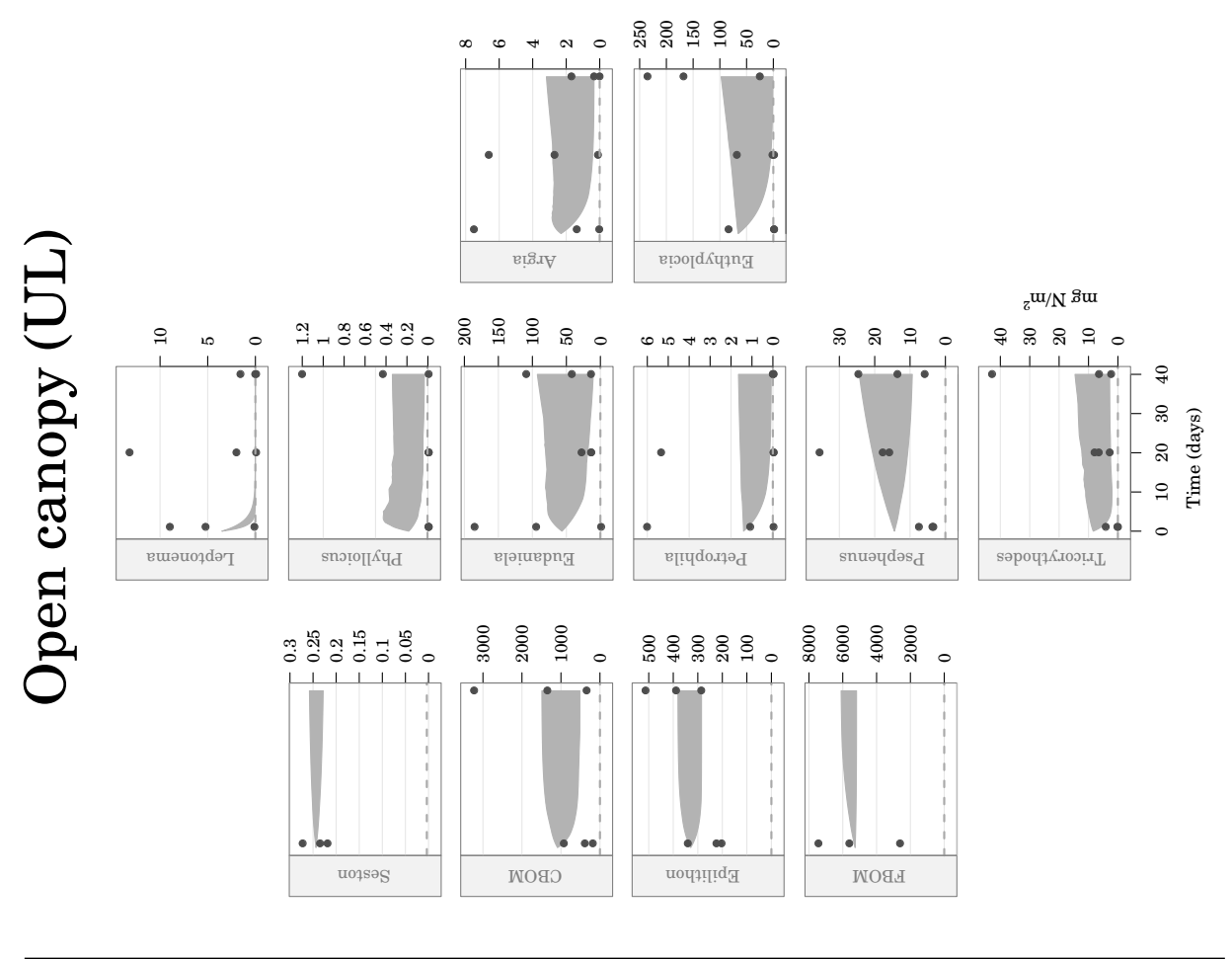

产

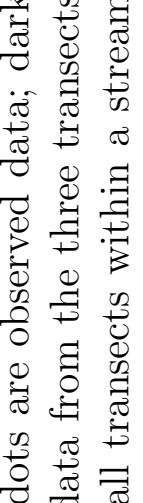

胥

- . $0 \Omega$

की

葛

응 范

乙

¿ $E$

응 छ

总荡

0 귱

귱

ठृ.

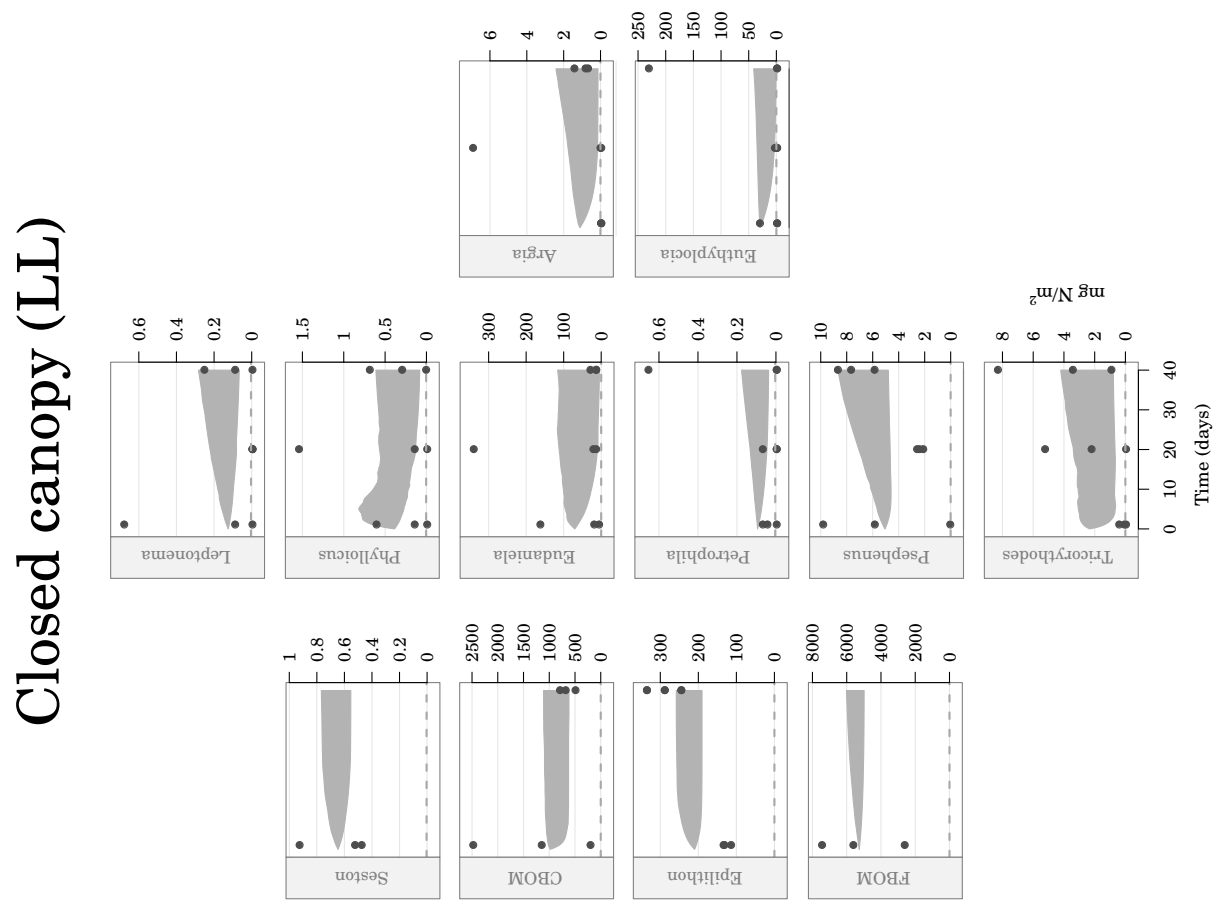

골

बृ 0

๘ b जٓ 크리요

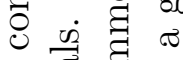
๑

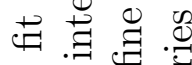
이잉 语 $\ddot{0} \circlearrowright$ i de 菏 .000

的

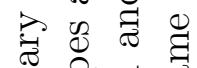

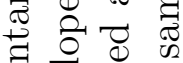

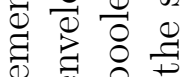
है च 


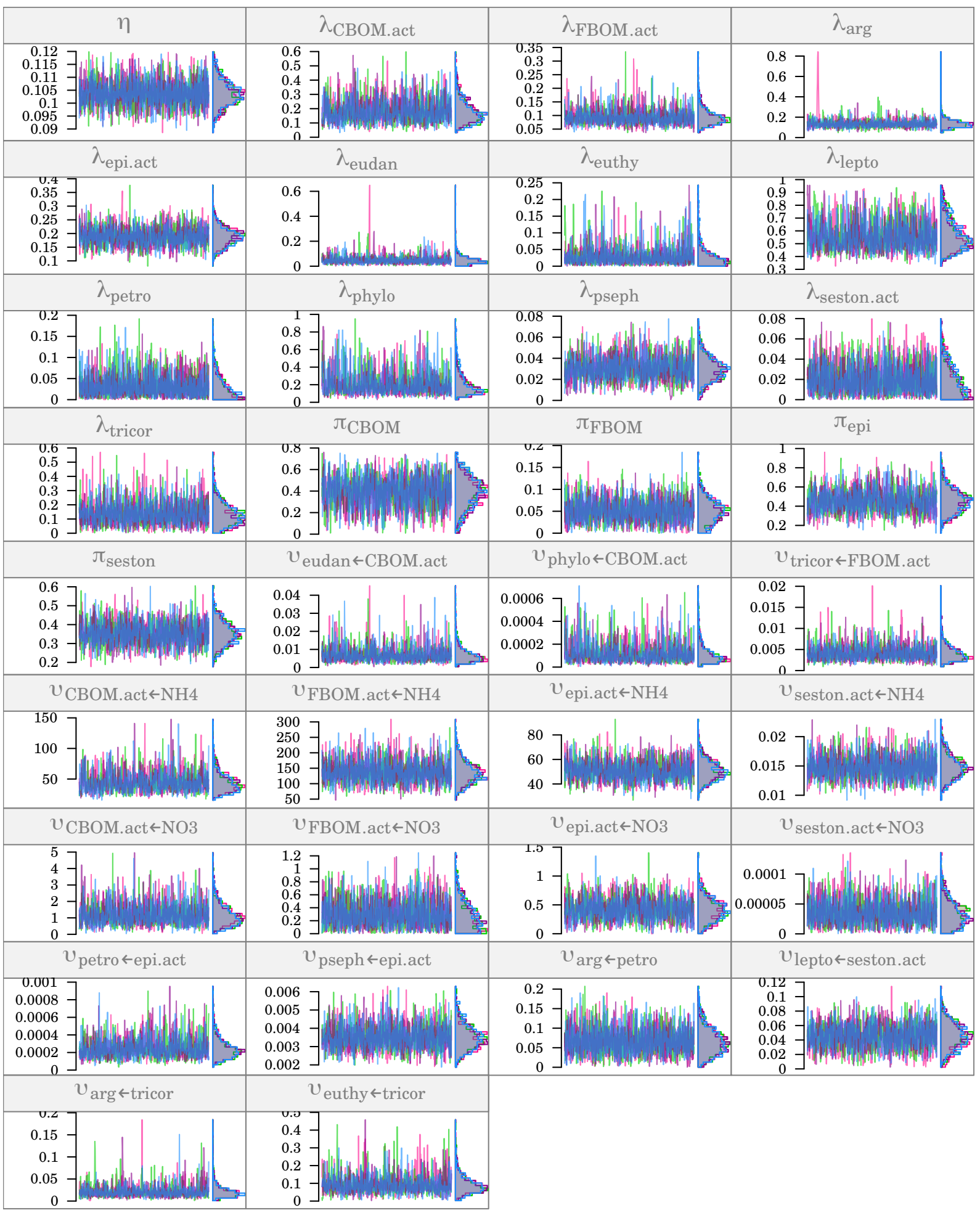

(a) Lower La Laja (LL) 


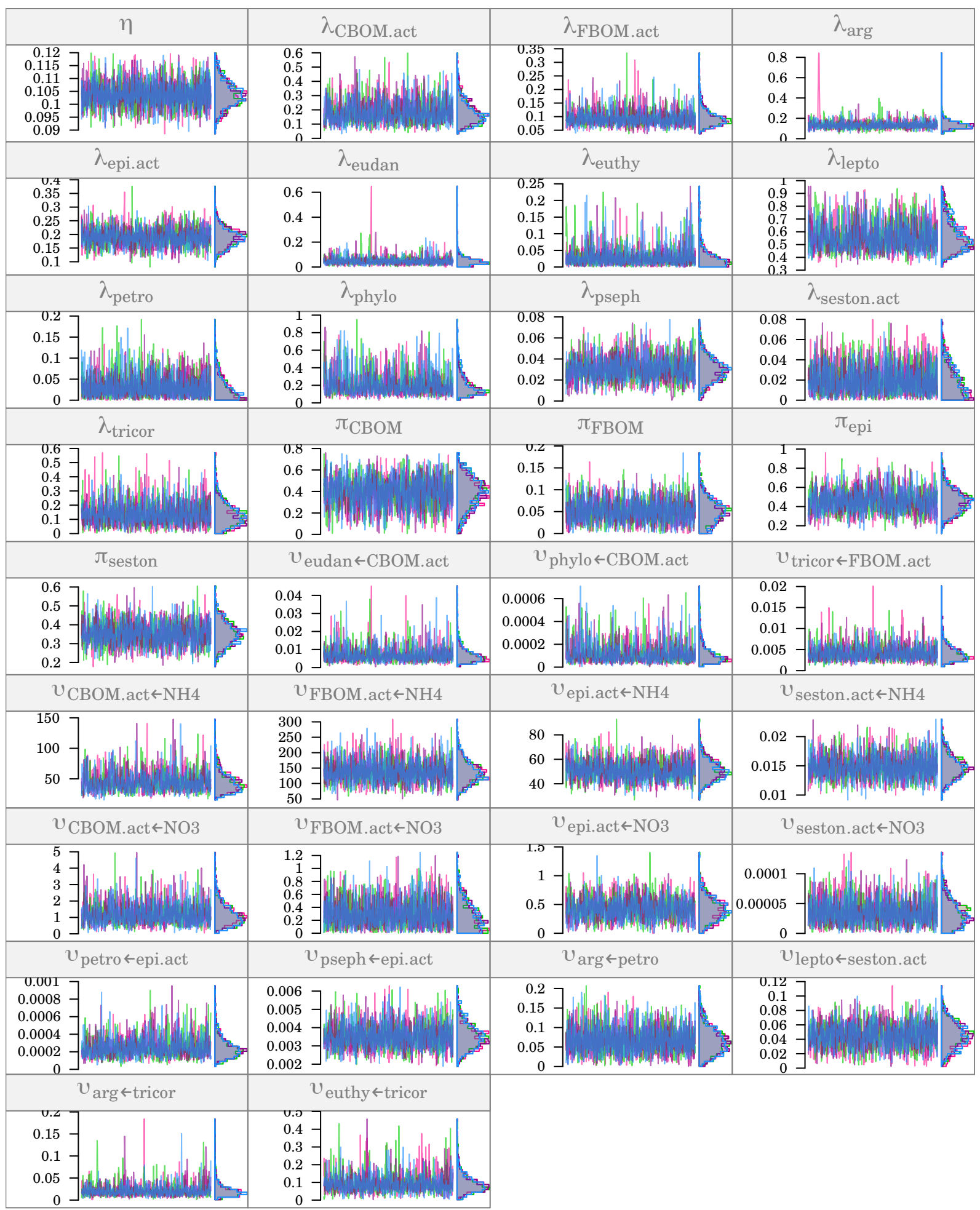

(b) Upper La Laja (UL)

Supplementary Figure 3: MCMC chains of primary parameters for the the final model fits. Four chains were run for each model. For each chain, the trace in the main panels and the density plot in the side panel are shown with matching color. 